N7417504

A A TE TEHAICAL PEPOPADUM

NASA TM $X-71500$

RESULTS FROM CASCADE THRUST REVERSER NOISE AND SUPPRESSION EXPERIMENTS

by O. A. Gutierrez, J. R. Stone, and R. Friedman

Lewis Research Center

Cleveland, Ohio 44135

TECHNICAL PAPER proposed for presentation at Twelfth Aerospace Sciences Meeting sponsored by the American Institute Aeronautics and Astronautics Washington, D. C., January 30-February 1, 1974 


\title{
RESULTS FROM GASCADE THRUST REVERSER NOISE AND SUPPRESSION EXPERIMENTS
}

\author{
Orlando A. Gutierrez, James R. Stone, and Robert Friedman \\ Aerospace Engineers \\ Lewis Research Center \\ National Aeronautics and Space Adninistration \\ Cleveland, Ohio
}

\begin{abstract}
Results from experimental work on rodel scale cascade reversers with cold airflow are presented. Sound power level directivity and spectral characteristics for cascade reversers are reported. Effect of cascade exit area ratio, vane profile shape, and enission arc are discussed. Model equivalent diameters varied from 3 to 5 inches; pressure ratios ranged from 1.15 to 3.0 . Depending on the reverser type, acoustic power was proportional to the $4 \frac{1}{2}$ to 6 th power of ideal jet velocity. Reverser noise peaked at higher frequency and vas more omidirectional than nozzlealone jet noise. Appreciable reduction in sideline noise was obtained from plane shields. Airfoil-vaned cascades were the most aerodynamically efficient and least noisy reversers. Scaling of cascade reverser data to example aircraft engines shoved all cascades above the 95 pNdB sideline goal for SIOL aircraft. Hovever, the airfoil-vaned reverser has a good potential for meeting this goal for high bypass (Iow pressure ratio) exhavsts.
\end{abstract}

\section{Introduction}

One of the aircraft noise sources that can becone important in meeting community noise regulations, especially for snall airgorts in heavily populated areas, is the thrust reverser used to reduce ground roll. There have been numerous studies of the aerodynamic performance of small size thrust reversers (e.g., ref. I); however, studies of reverser noise have not been available in the literature. For this reason, the NASALewis Research Center has been conducting an investigation of the noise characteristics of various types of reversers, including target-type reversers for circular and slot nozzles, and cascade reversers with and without shielding. This information, together with cost, aerodynamic efficiency and mechanical feasibility considerations, should be of value in the design of reversers for a wide range of engine applications.

Results of target-type reverser noise studies have been presented in references 2 to 5 . A correlation of sone of the data from reference 2 is presented in reference 6. Preliminary results for cascade reverser noise are now available fron cold flor model tests of cascade configurations with airfoil shaped vanes and constant-thickness vanes. Variables investigated in these tests included ratio of cascade exit area to duct inlet area, shape of duct deflector-blocker, and emission arc. These variables were studied over an ideal jet velocity range of 500 to 1300 fps, corresponding to pressure ratios of 1.15 to 3.0 . Shielding tests on one 
of the cascade configurations were made with both hard and acoustically soft shields.

This paper presents a preliminary summary of the results of the noise characteristics of the cascade reverser configurations tested. Results presented include data on reverser aerodynamic characteristics (such as reverse-thrust coefficient and specific mass flow) as well as noise data. Cascade reverser noise characteristics are presented in terms of sound power, directivity pattern, and spectra. Correlations of spectral data are given, and a comparison is made of calculated sideline perceived noise level at STOL aircraft scale for both cascade and targettype reversers.

\section{Cascade Reverser Models}

Cascade reversers consist of a series of vanes located in the walls of the turbine or fan duct upstream of the conventional exhaust nozzle. For reverse thrust, the exhaust nozzle is blocked and the flow deflected through the uncovered cascade vanes. The cascade reverser thus becomes a new exit nozzle and must be designed to match engine operating characteristics. In comparison, target reversers, which are simply deployed behind the conventional exhaust nozzle, will not affect the engine cycle provided they are farther than a minimum critical distance from the nozzle and thereby do not back-pressure the engine.

Design considerations for cascade reversers include the exit-toinlet area ratio, emission arc, vane characteristics such as blade inlet and outlet angles, spacing, curvature, solidity, profile shape (passage area variation), and type of inlet flow deflector-blocker.

Two cascade reverser models were used in this study. Their pertinent geometric characteristics are given in table 1 and the configurations are shown in figures 1 to 5.

Thin Vane Cascade

The first cascade reverser was made of thin (1/32 in.) constantthickness vanes. As shown in figure 1 , the vanes were set in two cascade sectors, each covering a $60^{\circ}$ arc on opposite sides of a 6-in. standard pipe ( $6 \frac{5}{8}$ in. O.D.). There were 5 parallel passages in each cascade sector. The vanes were of the impulse type, with inlet and outlet angles of $30^{\circ}$ to the axis. The cascade solidity, c/s, was 1.33 ; the vane spacing, $\mathrm{s}$, was $0.688 \mathrm{in}$. and the vane chord, $\mathrm{c}, 0.898 \mathrm{in}$. The cross sectional area of the duct ahead of the cascade, $A_{i n}$, was $18.25 \mathrm{in}^{2}$ and it is referred to as the inlet area to the cascade. The cascade exit area is defined as the cylindrical area at the exit radius of the cascade multiplied by the sine of the blade exit angle:

$$
A_{e x}=5 A_{e x}^{\prime}=522 \pi R_{0} \frac{60}{360} S \sin \alpha
$$

Al1 terms are defined in the list of symbols. 
The exit area, $A_{e x}$, was 0.65 of the inlet area, which for this particular configuration, represented the minimum physical flow area through the cascade. This made the cascade flow passage correspond aerodynamically to a convergent nozzle. This sma11 exit-to-inlet area ratio cascade design would be applicable to a circular engine duct with a high rozzle pressure ratio such as 2.5 .

A cowling with the same angle as the cascade vanes was installed forward of the cascade assembly to prevent direct impingement of reversed flow upon the mating flange in case of flow attachment. The thin-vane cascade was tested with two different flow blockers: a flat rear blocker set about 8 inches downstream of the cascade sector; and a fixed deflector-blocker consisting of a solid cylindrical insert with two plane $30^{\circ}$ wedge cuts ending even with the cascade rearmost vanes. No adjustment of the blocker position was possible on this design. A photograph of this cascade mode 1 is shown in figure 2 .

Airfoil Vane Cascade

The second cascade design (fig. 3) had airfoil-shaped, thick vanes. The impulse type vanes in this design had flow inlet and exit angles of $45^{\circ}$. The vanes were set in 8 equal size, separate sectors covering a possible total emission arc of $340^{\circ}$. Each sector had 12 vanes. An axially adjustable conical blocker allowed selection of the number of blades to be made active. Each cascade sector $\left(42.5^{\circ}\right.$ arc) could be replaced with a blanking plate. Therefore, a large range of emission arcs, blade number combinations and exit-to-inlet area ratios could be examined. The blocker was slid over a center body which converted the approach to the cascades into an annulus.

The airfoil vane cascade design varies significantly from the thin vane design of the other model. The minimum physical flow area for each passage, Amin, occurs near the inlet edge of the vanes. (This value is about 0.75 of the cascade exit area.) This cascade therefore is in effect a convergent-divergent flow passage. Dimensional details appear in figure 3, table 1 , and in reference 7. A photograph appears in figure 4.

Two major series of tests were run with the airfoil-shaped cascade: a series with variable emission arcs and nearly constant exit area; and another with a fixed emission arc and a variable exit area. Figure 5 shows the code used to identify the different variations of the airfoilshaped cascade configuration investigated. This consists of a sketch of an annular area divided into 8 sectors followed by a number. The annular area will show those sectors which are blocked to flow as blacked out. The number will represent the number of active vane passages for each sector. Table 2 gives details of the different configurations tested with the airfoil shaped cascade. The configurations with the large $A_{e x} / A_{i n}$ are representative of cascades used in $10 w$ (1.15 to 1.45$)$ pressure ratio fan ducts. The small values of $A_{e x} / A_{i n}$ would be applicable to high pressure ratio engines. It should be noted that for configurations with $A_{e x} / A_{i n}$ larger than 1.25 , the minimum physical flow area 
occurs at the duct inlet station, which can occur in engines with low pressure ratios.

Test Facility and Procedure

$\underline{\text { Rigs }}$

The cascade reverser experimental data were obtained on two separate flow systems. The noise data were taken on an acoustic rig designed to minimize internal noise and instrumented to obtain detailed acoustic data. Another airflow rig was used to obtain exhaust-jet velocity surveys and data on thrust-reversal performance. The airflow rig was essentially as described in reference 8 , but for the thrust reverser tests the piping was extended far enough to let the existing velocity survey equipment be used in the reversed jets. Reverse thrust was measured by preloading the axial thrust load cell with 500 lbs in weights hung from pulleys.

The acoustic rig is shown in figure 6 . Compressed air from a 140 psi abs source was supplied to the reverser at near ambient temperature $\left(60^{\circ}\right.$ to $\left.80^{\circ} \mathrm{F}\right)$ by an 8 -in. diameter pipe. This pipe was equipped with a flow-measuring orifice, a remotely operated flow control valve, a noise muffler, and a straight run ending at the nozzle, which was 63 inches above ground leve1.

The noise data were measured by nine condenser microphones with individual wind screens, located on a semicircle of 15 foot radius centered on the middle of the reverser exit plane. These microphones were spaced at $20^{\circ}$ increments from $\theta=20^{\circ}$ to $180^{\circ}$ from the pipe inlet centerline, at the same height above the smooth asphalt surface as the pipe centerline.

$\underline{\text { Procedure }}$

Aerodynamic and acoustic tests were performed on all the cascade reverser configurations. For each configuration the nozzle inlet total pressure was varied to give a series of nozzle pressure ratios, nominally $1.15,1.25,1.40,1.72,2.00,2.50$, and when possible 3.0, al1 at near ambient total temperature $\left(60^{\circ}\right.$ to $\left.80^{\circ} \mathrm{F}\right)$. Flow data were recorded for al1 tests, as well as necessary pressure and temperature readings to ca1culate ideal exhaust velocity.

In the aerodynamic tests, axial force measurements to determine reverse thrust were taken in addition to the other aerodynamic readings. Axial traverses of outlet velocity were taken at one circumferential position at the exit of the cascades.

In the acoustic tests, after flow conditions had stabilized, flow parameters and atmospheric conditions were recorded together with the noise data from each of the nine microphones in the far field polar array. The noise data were analyzed directly by use of a 1/3-octave band analyzer and recorded on magnetic tape for computer processing. The microphones were calibrated at the start and end of each day's running 
with a standard piston calibrator. A variation of \pm 0.5 dB during the day was considered acceptable.

The 1/3-octave-band analyzer yielded the sound pressure leve1, SPL, in each band from 50 to $20.000 \mathrm{~Hz}$. These data were corrected for atmospheric absorption, and the overall sound pressure level, OASPL, was computed for each microphone. The nominal spectral sound power level, FWL, and the nominal overall sound power level, OAPWL, were obtained by integration. These power levels are termed "nominal" since the noise measured is a function of the azimuthal angle while the integration assumes symmetry about the jet axis.

Detailed ground reflection corrections are not made herein. The microphone data are corrected only for this facility's high-frequency asymptotic reflection of $2.2 \mathrm{~dB}$. Furthermore, no data points falling within $5 \mathrm{~dB}$ of the upper limit of background noise at a given frequency are presented.

\section{Results and Discussion}

Aerodynamic and acoustic results obtained with the cascade thrust reversers are presented in graphical form. Aerodynamic results are presented as reverse thrust ratios, reverse thrust coefficients, and specific weight flows. Acoustic results are shown as graphs of sound power, OASPL directivity and SPL spectra in direction of maximum OASPE. In addition, complete tables of 1/3-octave band roise spectra for all microphone locations are available, on request, from the authors.

Aerodynamic Results

Reverse thrust ratios are shown in figure 7 for all the configurations tested. The reverse thrust ratio, $c_{R}$, is the ratio of the measured reverse thrust, $F_{R}$, to the forward thrust possible from the same mass flow rate at the ideal jet velocity, mij. This ratio is plotted against the stagnation Mach number $\mathrm{U}_{j} / \mathrm{c}_{0}$, defined as the ratio of ideal isentropic fully expanded jet velocity to the velocity of sound at ambient conditions, $\mathrm{c}_{0}$.

The thin-vaned cascade reversers had a markedly lower reverse thrust ratio than the airfoil-vaned cascades. The application of the deflectorblocker to the thin-vaned cascade with flat blocker improved its reverse thrust ratio from approximately 0.35 (same as obtained with the V-gutter target reverser of ref. 4) to about 0.45 . In both cases velocity traverses taken at the exit of the cascades indicated flow separation, with jets exiting at angles of axound $50^{\circ}$ from the axis rather than at the vane exit angle of $30^{\circ}$.

The low level of reverse thrust from the thin-vane cascade is most likely caused by flow separation resulting from the poor flow area distribution along the vane chord. The physical flow area in the direction of the vane at the vane inlet radius is slightly larger than at the exit 
radius. However, at the point of inflection within the vane the available area ratio is double the exit area. The large flow area expansion would result in excessive velocity diffusion on the vane surfaces. In addition, the poor guidance from the inlet station to the vane inlet with the flat blocker is an additional source of losses which is partially eliminated with the use of the deflector-blocker.

The airfoil-vaned cascade, as shown in figures 7 (b) and (c), had reverse thrust ratios ranging between 0.6 and 0.7 , depending on the stagnation Mach number. The one exception was the 5 -vane cascade with a $340^{\circ}$ emission arc which had higher values at the lower values of $\mathrm{U}_{j} / \mathrm{c}_{\mathrm{o}}$. Traverses taken at the cascade exits showed all but the $340^{\circ}$ emission arc configuration had flow leaving the blades at $45^{\circ}$ from the axis, indicating good flow attachment to the blades. However, the flow from the $340^{\circ}$ emission arc cascade configuration $\left(A_{e x} / A_{i n}=1.25\right)$ was found to be attached to the outside wall of the inlet pipe. This attachment was responsible for the odd variation in reverse thrust ratio shown for this case in figure $7(\mathrm{~b})$.

The aerodynamic characteristics of the reversers are also shown in figure 8 in terms of specific mass flow and reverse thrust coefficient plotted against pressure ratio. Specific mass flow rate, defined as $\dot{\mathrm{m}} \sqrt{\mathrm{RT} / \mathrm{g}_{\mathrm{c}}} / \mathrm{P}_{\mathrm{t}} \mathrm{A}_{\mathrm{min}}$ is plotted in figure $8(\mathrm{a})$. The data show the parameter to approach a constant value between pressure ratios of 1.72 and 2.0 , indicating choked flow. Below pressure ratios of 1.72 , the specific mass flow rate varies with pressure ratio as would be the case with unchoked flow. The specific mass flow rate value for isentropic sonic flow is shown for comparison. Values for all cascades, thin vane as well as airfoil, collapsed into a narrow band of values.

The reverse thrust coefficient, $c_{f}$, shown in figure $8(b)$ is the reverse thrust ratio of figure 7 divided by the cosine of the vane exit angle. This coefficient represents the ratio of measured reverse thrust to the maximum obtainable by a perfect turning of the same mass flow rate by the cascade vanes. The difference between the airfoil-vaned cascade and the thin-vaned cascade become more marked when shown on this basis. The thin-vaned cascades, with its separated flow, achieved coefficients of only 0.4 to 0.6 , while all the airfoil cascades had reverse thrust coefficients between 0.8 and 1.0 . The flow attachment to the inlet pipe observed on the airfoil configuration with the $340^{\circ}$ emission arc results on reverse thrust coefficients above 1.1 due to the over turning.

Thin-Vaned Cascade Reverser Acoustic Results

Sound Power Leve1. The nominal overall sound power leve1, OAPWL, for the thin-vaned cascade reversers are shown in figure 9. The OAPWL is shown normalized by $\rho_{\mathrm{o}} \mathrm{A}_{\mathrm{e}} \mathrm{U}_{j}^{3}$ and plotted against the stagnation Mach number, $\mathrm{U}_{\mathrm{j}} / \mathrm{c}_{\mathrm{o}}$. The area used in this term, $\mathrm{A}_{e}$, is the equivalent area required to flow the measured mass flow rate at the ideal fully expanded jet velocity, 


$$
A_{e}=\frac{\dot{m}}{\rho U_{j}}
$$

The values of $A_{e}$ are a function of operating conditions. They are shown as ratios of exit area, $A_{e} / A_{e x}$, in table 3 .

The normalized acoustic power appears to vary as the fifth power of the ideal fully expanded jet velocity ( $c_{0}$ was essentially constant for the data). The deflector-blocker decreased the noise generation by $4 \frac{1}{2} \mathrm{~dB}$. This reduction in noise level is significant, because it is achieved with an increase of about 25 percent in reverse thrust (Fig. 7(a)). Data from a cold flow convergent nozzle-alone curve from reference 2 , is also shown as a dotted line for comparison purposes. At $\mathrm{U}_{j} / \mathrm{c}_{0} \geq 1.1$ the reverser normalized OAPWL appears lower than that for the convergent nozzle. This could be due to different shock patterns in the cascade exit flow or to different effective velocity values between the cascade and the nozzle.

For comparison purposes, similarly normalized OAPWL data are presented in figure 10 for a variety of target reverser configurations from references 2, 3, and 5. The shaded area shown for the V-gutter target and 69 -aspect ratio slot represents the range of data obtained over a range of variables, such as reverser plate angle, length, spacing, and offset. Normalized OAPWL varied as the sixth power of stagnation Mach number (ideal jet velocity) for all target reverser cases, as compared to the fifth power for the cascade reverser. The absolute power level of the thin-vane cascade with deflector blocker was about the same as the lowest values obtained with the target reversers.

Directivity. The directivity on the centerline plane of the thinbladed cascade reverser noise is shown in figure 11. The difference between the OASPL at a given angle and the maximum OASPL is plotted as a function of polar angle. In all cases the directivity is miuch more uniform than for the nozzle-alone jet directivity shown in reference 2 . The maximum deviation between minimum and maximum reversed OASPL is $5.5 \mathrm{~dB}$. This difference occurs at the $60^{\circ}$ angle, where the microphone is being impinged by the exiting jet. The direction of maximum OASPL shifts with velocity. At the lower velocity, or pressure ratios, the maximum noise appears at $100^{\circ}$ from the inlet axis for the flat blocker cascade, and at $140^{\circ}$ for the deflector-bIocker. At higher pressure ratios the maximum OASPL occurs at $20^{\circ}$ for both.

For the deflector-blocker cascade, the peak OASPL direction at low velocities occurs around $90^{\circ}$ from the direction of the exiting jets (typical of dipole noise), while at the higher velocities, the $20^{\circ}$ angle from the inlet appears close to the direction where jet noise should peak. The directivity of the peak noise for the cascade with flat blocker at low velocities $\left(100^{\circ}\right.$ from inlet axis) does not present as clear a picture of the dominant noise source.

Spectra. The SPI spectra in the direction of maximum OASPI for both 
types of blocker used with the thin-bladed cascade reverser are shown in figure 12. For the flat blocker, figure 12(a), the spectra do not change in general shape with velocity. At the lower velocities, low frequency tones tend to dominate the spectra. The intensity of these tones appears to increase with the third power of velocity, and is no longer dominant at a stagnation Mach number of around 0.67 . There is a shift in the peak noise frequency from 6.0 to $2.5 \mathrm{kHz}$ as the Mach number increases.

Similar spectra for the deflector-blocker cascade appear in figure 12(b). The most obvious conclusion is that the deflector-blocker eliminated the low frequency tones present with the flat blocker. Also, in this case, the spectral components of the maximum OASPL shift appreciably with velocity. The low velocity cases, peaking at $140^{\circ}$, are dominated by high frequency noise, while the higher velocity cases have lower frequency components which can be associated with either jet noise or shock noise, and are as dominant as the high frequency noise. These components are also the cause of the shift in the maximum directivity to the $20^{\circ}$ angle.

Sideline Shielding. Tests were conducted using the thin-vaned cascade reverser with the deflector blocker to determine the effectiveness of shields or side plates on deflecting noise away from the sideline, thereby reducing the noise level in that direction. The shields used are shown in figure 13. They consisted of plates 11 inches wide and 24 inches long mounted at $60^{\circ}$ to the inlet axis. These shields were tested with and without a 1-inch layer of broadband (bulk-type) acoustic insulation over the plates, as well as over the duct cowling. The leading edges of the plates were even with the forwardmost opening of the cascade and shielded the line of sight from the cascade to the sideline at angles from $90^{\circ}$ to $180^{\circ}$ from the inlet axis. The actual test plates were long with respect to the cascade body to allow mounting from the rear face of the cascade assembly. The shielding characteristics should be the same for a corresponding flight-size shield as shown by dotted lines in figure 13. However, caution must be exercised in sizing and spacing the shields. If the shields are placed too close to the exiting jets they might introduce additional sources of low frequency noise as discussed in the shielding studies of reference 9 .

Shielding tests results are shown in figure 14 for two different pressure ratios. The hard shields gave an appreciable reduction in OASPL for angles greater than $80^{\circ}$ from the inlet axis. As much as a $5 \mathrm{~dB}$ reduction was obtained at angles of $100^{\circ}$ and $180^{\circ}$. At low angles, the OASPL actually increased somewhat due to reflection from the shields. Addition of acoustic insulation to the shielding plates and cowling produced a significant reduction in the noise at angles smaller than $120^{\circ}$. However, the effect of the insulation at angles greater than $120^{\circ}$ was relatively minor.

Airfoil-Shaped Cascade Reversers Acoustic Results

Sound Power Level. Normalized OAPWL's are shown in figure 15 as a 
function of stagnation Mach number for all airfoil cascade reverser configurations tested. The figure includes the variations in emission arc at exit-to-inlet area ratios between 1.25 and 1.68 , and the variation in area ratio from 0.50 to 1.49 at constant emission arc. There is an obvious change in the slope of the acoustic efficiency curves for the different variations as well as a change in level. The shift in slope seems to be related to the exit-to-inlet area ratio of the airfoil-vaned cascade.

The cascades tested at variable emission arc with exit-to-inlet area ratios above 1.25 have the highest noise levels. All four of the cascade configurations in this group deviate from a constant exponent relation with Mach number. The slope that best fits these data gives a $4 \frac{1}{2}$ power dependency of acoustic power on ideal jet velocity within a scatter band of $\pm 3 \mathrm{~dB}$. There is no apparent separation between these individual configurations.

The cascade configurations with a constant circumferential emission arc of $170^{\circ}$ showed a marked change in slope and level of the normalized OAPWL when the exit-to-inlet area ratio decreased below a value of around 1.0. At a value of 0.99 the acoustic power became a very orderly function of the $5 \frac{1}{4}$ power of velocity. A decrease of the area ratio to 0.75 reduced the acoustic power to a still lower magnitude and made it proportional to the sixth power of the velocity. A further decrease in the area ratio to 0.62 and to 0.50 did not change the normalized OAPWL. It is also noted that as the stagnation Mach number approaches 1.0 , the reverser normalized OAPWL follows very closely the relationship obtained in reference 2 for a convergent nozzle alone.

Comparison of figures 9,10 , and 15 shows that the airfoil-shaped cascade reverser with exit-to-inlet area ratio smaller than 1 has the lowest normalized OAPWL of all the cascade or target reversers tested. Since the reverse thrust ratio for the small area ratio airfoil-bladed cascade reverser is as high or higher than for any other reverser (fig. 7), these configurations appear to have the most satisfactory reverse thrustto-noise ratio of all the reverser models investigated. However, as previously mentioned, the cascade type reversers must be designed to match engine operating characteristics. In many instances the most satisfactory cascade reversers from a noise standpoint may not necessarily be suitable for a particular engine or fan application.

The sound power level data for the $170^{\circ}$ emission arc cascades shown in figure 15 have been replotted in figure 16 to show the effect of cascade area ratio. Values of OAPWL are plotted as a function of area ratio, $A_{e x} / A_{i n}$, for constant values of pressure ratio. In addition, a reference linear variation of acoustic power with exit area is shown by the dashed Iine. For area ratios up to $A_{e x} / A_{i n}=0.75$, the OAPWL is essentially proportional to the area ratio over the pressure ratio range of 1.15 to 3.0. However, as the area ratio increases beyond 0.75 , the OAPWL increases faster than the area ratio for pressure ratios between 1.15 and 2.0. The area ratio effect on OAPWL is the greatest at $P R=1.15$ and 
decreases as the pressure ratio increases. At pressure ratios above 2.0, the OAPWL is again directly proportional to the area ratio throughout the area ratio range.

The lower crosshatched section shown in figure 16 represents the expected pressure ratio - area ratio zone of interest for low pressure fans applicable to externally-blown-flap STOL engines. The upper crosshatched section is representative of the operating zone for engine exhaust ducts at high pressure ratio, such as used in CTOL engines, and such STOL applications as the augmenter wing and core engines.

Directivity. Typical OASPL directivity plots are shown in figure 17 for the airfoil-vaned cascade with $170^{\circ}$ emission arc and area ratios of $0.5,0.99$, and 1.48. As with all reversers tested, the OASPL distribution is much more omnidirectional than for pure jet noise. The greatest deviation from the maximum OASPL shown in figure 17 is $5 \frac{1}{2} \mathrm{~dB}$. As with the thin-bladed cascade reverser, directivity is a function of the exit ideal jet velocity. For the lower velocities (up to a $U_{j} / c_{0}$ value of 0.67 ), the peak OASPL occurs at $120^{\circ}$ to $140^{\circ}$ from the inlet axis, which is nearly $90^{\circ}$ from the direction of the exiting jets. At the higher velocities $\left(U_{j} / c_{o}\right.$ above 0.95$)$ the peak OASPL shifts to angles of $20^{\circ}$ to $60^{\circ}$ from the inlet axis, which is approximately $15^{\circ}$ to $20^{\circ}$ on either side of the exiting jets. At intermediate velocities $\left(U_{j} / c_{o}\right.$ between 0.67 and $0.95)$, the directivity is more uniform.

These directivity shifts imply that both surface-generated noise (dipole) and jet-generated noise (quadrupole) exist, with surfacegenerated noise controlling at the low velocities and jet noise at the high velocities. The shifts start before ideal sonic conditions are reached. The airfoil-shaped cascade configurations with large area ratios (directivity plots not shown) present similar trends.

Spectra. Sound pressure level spectra in the direction of maximum OASPL for the airfoil cascade reverser are shown in figure 18. The spectra cover the stagnation Mach number range from 0.44 to 1.16 . The case shown is for the cascade with $170^{\circ}$ emission arc and 8 blades (exit-toinlet area ratio of 0.99 ). The spectra for the lower velocities is dominated by high frequency noise in the range from 8 to $12.5 \mathrm{KHz}$. The two higher velocity cases are dominated by lower frequency noise at 1 to $2.5 \mathrm{KHz}$. At the intermediate velocities (stagnation Mach numbers of 0.85 and 0.95 ), the spectra are relatively flat above a frequency of $0.6 \mathrm{KHz}$. These changes in spectral shape seem to be related to the changes in directivity of the peak OASPL noise.

A direct comparison of the spectra for the same reverser configuration at the three angles of maximum OASPL given in figure 18 is shown in figure 19 for 3 velocity levels. The shape of the spectra at the $140^{\circ}$ angle changes very little over the range of $\mathrm{U}_{j} / \mathrm{c}_{0}$; it is always dominated by the high frequency noise. The spectra at the other two angles $\left(20^{\circ}\right.$ and $60^{\circ}$ from the inlet axis), change appreciably with a change in $\mathrm{U}_{\mathrm{j}} / \mathrm{c}_{\mathrm{o}}$. At the low value of $\mathrm{U}_{\mathrm{j}} / \mathrm{c}_{\mathrm{o}}$, the spectra are high-frequency domi- 
nated having a spectral shape similar to that at $140^{\circ}$. As the velocity increases, sound pressure levels for the lower frequencies increase more rapidly than for the high frequencies until they become dominant. At the $20^{\circ}$ to $60^{\circ}$ angles, for instance, the $1 \mathrm{KHz}$ frequency increased as the $8 \mathrm{th}$ power of velocity, while the $8 \mathrm{KHz}$ frequency increased as the 6 th power of the velocity. The implication is that at Iow velocities the cascade reverser noise is dominated by high frequency, dipole-type noise throughout the whole radiation arc, and as the velocity increases the jet-type noise becomes important at angles near the jet exit. At the higher velocities, jet noise controls the spectra, except that the high frequency roli-off rate is reduced.

Figure 20 shows noise spectra for the airfoil-shaped cascade reverser with a constant $170^{\circ}$ emission arc and variable area ratios from 0.5 to 1.49. The spectra shown are for a pressure ratio of $1.25\left(\mathrm{U}_{j} / \mathrm{c}_{0}=0.55\right)$ in the direction of maximum OASPL. The shape of the spectra is the same for all the configurations up to an area ratio of 0.99 ( 8 vanes), and their characteristics have been discussed already. For the area ratio 1.49 case (12 vanes), very high level narrow-band frequency noise appears at the 0.8 and $8 \mathrm{KHz} 1 / 3$-octave bands. The narrow band noise at $8 \mathrm{KHz}$ completely dominates the noise level. This narrow band noise appears in the spectra for all the airfoil cascade reverser configurations tested at the area ratios larger than one, as shown in figure 2I. The narrow band frequency noise was the dominant source of noise for the large exitto-inlet area ratio airfoil cascades at the lower pressure ratios, but they were not noticeable at pressure ratios above $1.72\left(\mathrm{U}_{j} / \mathrm{c}_{0} \geq 0.85\right)$. No tones were observed with the thin vane cascade $\left(A_{e x} / A_{i n}=0.62\right)$.

Although the exact cause of the high frequency tones in figure 21 is not known, there are a number of possible mechanisms that could give rise to such tones: mechanical resonance; subsonic feedback (screech); trailing vortex sheet; and flow oscillations producing fluctuating vane lift. Most of these sources would be suppressed with the onset of choked flow or sonic velocities. However, the reason for the appearance of tone noise only for the high area ratio configurations is not clear. For area ratios greater than 1.0 , the cascade tends to represent a diffuser with parallel flow passages. Such a configuration may be susceptible to flow instabilities both within a vane passage and from passage to passage. However, whatever the source, the high frequency tones are the cause of the irregular variation of acoustic power with velocity level previously discussed (fig. 15) for the airfoil-shaped cascade reverser configuration with area ratio greater than one.

\section{Correlation of Cascade Reverser Power Spectra}

No single parameter was found capable of correlating the normalized sound power level spectra for all the cascade reversers throughout the entire range of velocities. In reality, there should not be such a parameter, because as shown previously, the cascade reverser noise is dominated by surface noise (dipole) at the low end of the velocity range and by jet noise (quadrupole) at the high end of the velocity range. In addition, there are the cases of large exit-to-inlet area ratio at low 
velocities which are dominated by narrow band noise.

The most successful approach at correlation used two distinct Strouha1 numbers: one for $\mathrm{U}_{j} / \mathrm{c}_{\mathrm{O}}$ equal or greater than 0.95 , another for $U_{j} / c_{o}$ less than 0.95 . The normalized PWL's for $U_{j} / c_{o}>0.95$ are shown in figure 22. The Strouhal number used is based on the equivalent diameter of the cascade reverser exit area, $D_{e x}=2\left[A_{e x} / \pi\right]^{1 / 2}$. This value of diameter is used for this jet noise dominated range as it would be a representative dimension of the exit jet size. The data throughout the normalized spectra for all reversers collapse relatively well.

Figure 23 presents the data for $U_{j} / c_{o}<0.85$. For this range where surface noise (dipole) dominates, a Strouhal number based on the cascade spacing, $\mathrm{s}$, was used.

Data for test conditions dominated by narrow band noise were excluded in this normalization. For the high frequencies, the agreement of the data are very good. However, at Strouhal number values below 0.1 , the data are no longer correlated. This is consistent with the previous observations that the high frequency data at lower velocities is controlled by a dipole noise source, while the low frequencies are jet generated (quadrupole noise) and therefore they depend more on the size of the jet. It should be noted that the same comparison would be obtained if the cascade chord length, $c$, had been used as the length dimension since all the cascades tested had the same solidity.

Comparison of Reverser Sideline Perceived Noise Level at Aircraft Scale

Estimates of perceived noise levels at the 500-foot sideline for sizes suitable to two distinct STOL aircraft applications have been made. One of the applications was to a high pressure ratio exhaust duct, the other to a low pressure ratio exhaust duct. In all cases, scaling was made to an arbitrary total engine thrust of 19000 pounds.

Assumptions made on scaling the reverser data to aircraft size were that frequency varies inversely with exhaust equivalent diameter and intensity varies directly with the square of the equivalent diameter. A high frequency roll-off of $2 \mathrm{~dB}$ per 1/3-octave band was assumed in order to estimate the SPL's for those frequency bands where there were no data due to scaling shifts. No specific aircraft configuration was considered, and no allowance was made for reflection from the aircraft. However, the ground reflections of the experimental data were included without correction. The data were corrected for atmospheric attenuation according to reference 10; no correction was made for extra ground attenuation. The perceived noise level for each angle was then calculated according to reference 11.

\section{High Pressure Ratio Engine}

In order to compare results directly with those presented in reference 5 for a V-gutter target reverser, a 19000 lb thrust engine exhaust with a 2.5 nozzle pressure ratio ( $D_{e}=28 \mathrm{in.}$ ) was chosen as the high 
pressure ratio engine for scaling purposes. The resulting perceived noise levels at the 500-foot sideline are shown in figure 24. The PNL's are shown for the V-gutter target reverser of reference 5 together with those for two cascade reversers: the thin-vane cascade reverser with deflector blocker ( $A_{e x} / A_{i n}=0.65,120^{\circ}$ emission arc) and the airfoilvane reverser with $170^{\circ}$ emission arc and 6 vanes $\left(A_{e x} / A_{i n}=0.75\right)$.

Figure 24(a) presents results for operation at full pressure ratio (2.5) which represents an ideal velocity of 1188 fps. The cascades would seem about 2 to 2.5 PNdB louder than the V-gutter reverser. However, for these not-very-different noise levels, the cascade reversers yield larger reversed thrust than the V-gutter reverser. This increase is about 35 percent for the thin bladed cascade and nearly 85 percent for the airfoil bladed cascade reverser.

Reevaluating the sideline PNL's for these same configurations on the basis of the same exhaust duct size as before but at the reduced ideal velocities (throttle settings) necessary to produce equal reversed thrust, the results of figure $24(\mathrm{~b})$ are obtained. The thin-vane cascade reverser is about 1 PNdB quieter and the airfoil-vane cascade reverser is 5 PNAB quieter than the V-gutter reverser. However, even the quietest of al1 these noise levels still show PNL values well above the 95 PNdB design goal for a STOL aircraft for a considerable distance along the sideline (single engine goal would be about 2 to 6 PNdB less, depending on number of engines and aircraft configuration).

Figure 25 shows the sideline shielding results with the thin vane cascade $\left(A_{e x} / A_{i n}=0.65\right)$ scaled to the same engine application described in figure $24(\mathrm{~b})$. The hard shields reduced the maximum sideline PNL by 6 PNdB while the insulation reduced it an additional 2 PNdB. Even with the shield, the single-engine maximum PNL is still well above the STOI. aircraft noise goal of 95 PNdB. However, the length along the sideline (measure of exposure time) for which the PNL is above the goal value has been reduced.

Although sideline shielding tests were not run with the airfoil vane cascade, an estimation can be made concerning the resultant perceived noise level for an airfoil vane cascade reverser with a treated sideline shield. If the effect of the shield on the PNL pattern were the same as for the thin vane cascade (fig. 25), then a corresponding decrease in maximum PNL due to shielding would be obtained ( 8 PNdB). This would stil1 produce a maximum PNL for the shielded airfoil vane cascade of figure $24(\mathrm{~b})$ around 4 PNAB above the 95 PNdB goal, but it would decrease appreciably the exposure time above that PNL value at the sideline.

The calculation of the previous figures were based on a ratio of reverse thrust to ideal exhaust thrust of around 0.35 for a high pressure ratio exhaust. If a higher value of reverse thrust ratio were required, perhaps 0.5 , the target-type reverser would not be capable of producing the required reverse thrust. Furthermore, the cascade-type reversers would have to operate at higher pressure ratios (higher ideal exhaust ve- 
locities), with resulting higher noise levels. However, required reverse thrust ratios less than the example of 0.35 would be very beneficial in reducing perceived noise because of reduced operating pressure ratios. Large reductions in noise would result in view of the steep variation of sound power with exhaust velocity $\left(\mathrm{U}_{j}^{6}\right)$ for low nominal area ratio cascades (figs. 9 and 15).

\section{Low Pressure Ratio Engine}

The low pressure ratio engine chosen for scaling was a 19000 pound thrust engine with a 1.25 nozzle pressure ratio $\left(D_{e}=59.7\right.$ in.). This would be representative of the fan stage of a high-bypass turbofan engine. Because of the low pressure ratio available in such engines, the value of $\mathrm{A}_{e} / \mathrm{A}_{\text {in }}$ for suitable cascade reversers would probably be about 1 or greater, as shown by the shaded area in figure 16 . The cascades chosen for scaling to the low pressure ratio engine size were the airfoil-vane cascade reversers with $170^{\circ}$ emission arc and $\mathrm{A}_{\mathrm{ex}} / \mathrm{A}_{\text {in }}=0.99$ and 1.49 ( 8 and 12 vanes, respectively). These two airfoil-vane cascades configurations are indicated in figure 16 by tailed symbols. The airfoilcascade that was scaled to the high pressure engine in the previous calculation is shown by the solid symbol in that figure.

The scaled PNL's for both airfoil-shaped cascade reversers are shown in figure 26. The PNL along the 500-foot sideline for the airfoil cascade scaled to the high pressure ratio engine for the same reversed thrust (12 $300 \mathrm{Ib})$ is shown as a dashed line for comparison. The $\mathrm{A}_{\text {ex }} / \mathrm{A}_{\text {in }}=0.99$ airfoil cascade, unshielded, was about $12 \mathrm{PNdB}$ quieter than the airfoil cascade reverser for the high pressure ratio engine. Assuming the same relative results as in figure 25, the addition of sideline shields would then reduce the peak sideline PNL to around 3 PNdB below the goal of 95 PNdB.

The calculation of figure 26 was for a ratio of reverse thrust to maximum engine thrust of 0.65 , which is the value of $c_{R}$ achieved with the airfoil vane cascade. However, an aircraft application would probably require a lower value of reverse thrust. For example, if the part throttle operating point was reduced to a fan pressure ratio of 1.15 , the ratio of reverse thrust to maximum engine thrust would be around 0.4 (assuming no change in cascade thrust coefficient). According to figure 16, a reduction in pressure ratio from 1.25 to 1.15 produced around a $5.5 \mathrm{~dB}$ reduction in overall sound power level for cascade area ratios between 1 and 1.5. Assuming as a first approximation that this decrease in OAPWL would be reflected as an equivalent decrease in PNL, then the maximum sideline PNL for the airfoil cascade $\left(A_{e x} / A_{i n}=0.99\right)$ partthrottle case might be at the $95 \mathrm{PNdB}$ level. With the use of sideline shields, the maximum PNL could be reduced to around 8 PNdB below the goal value. Thus, it appears possible to obtain thrust reversers for low pressure ratio engine applications that have a potential for meeting the 95 PNdB aircraft noise goal.

The above comparisons are valid specifically for the assumptions 
made. However, caution should be exercised as some of these assumptions may not be applicable when limited by mechanical feasibility considerations. For instance, the geometric scaling assumption requires that the cascade vanes for the engine with $D_{e}=59.7$ inches must have a 7 -inch chord which would require an increase of over one foot on the duct diameter just for stowing purposes. If the vanes dimensions are not increased in the same proportion as the cascade area, the dipole noise (controlled by vane dimensions) and the jet noise (controlled by total cascade area) should scale by different values, resulting in changes in spectral distribution and atmospheric attenuation. These changes will, of course, alter the sideline PNL obtained.

\section{Summary of Results}

This paper has presented results of cold-flow, model scale, cascade thrust reverser noise tests conducted at Lewis Research Center. Thinand airfoil-shaped cascade reversers and shielding tests were covered. The main results can be summarized as follows:

1. Reverse thrust ratios for the airfoil-shaped cascade reversers ranged from 0.6 to 0.7 as compared to 0.35 to 0.5 for the thin-vane cascades. These values compare with ratios of around 0.35 for target-type reversers tested previously.

2. All reversers generated more noise than a jet alone at subsonic exhaust flow conditions. At supersonic flow conditions the normalized overal1 sound power level of all reversers tested became about equal to that for cold supersonic jets. A cascade reverser with airfoil shaped vanes and a nominal ratio of cascade exit area to duct inlet area smaller than 0.75 was the quietest reverser tested.

3. The acoustic power of the cascade reversers was dependent on the $4 \frac{1}{2}$ to 6 th power of the ideal jet velocity, depending on reverser area ratio and pressure ratio (target reversers varied as the 6 th power of the velocity).

4. Cascade reverser noise was strongly dependent on cascade geometry. In general, the thin-vaned cascades were noisier than the airfoil-vaned cascades. The type of deflector that guided the flow into the cascade had a $4 \frac{1}{2} \mathrm{~dB}$ effect on the noise from the thin-vaned cascade reverser. The exit-to-inlet area of the cascade reverser seems to be an important acoustic design parameter. The configurations tested showed that area ratios greater than one had very intense narrow band noises that made the reversers much louder than expected at low pressure ratios.

5. Results showed reverser noise to be a combination of noise sources. At low velocities, dipole noise created by the surface dominated. At higher velocities, the quadrupole jet mixing noise and shock noise appeared dominant. This change also caused shifts in the direction where the maximum OASPL appeared. In addition, narrow band noises may be present at subsonic exhaust velocities capable of dominating all other sources. 
6. Noise directivity patterns for reversers are very uniform. Maximum variation in OASPL encountered around the polar arc was $5 \mathrm{~dB}$.

7. The airfoil-shaped cascade reverser (quietest of a11 tested) scaled to a $19000 \mathrm{lb}$ thrust engine at high (2.5) exhaust pressure ratio produced $11 \mathrm{PNdB}$ above the goal of $95 \mathrm{PNdB}$ at the $500-\mathrm{ft}$ sideline for STOL aircraft while yielding a reversed-to-forward thrust ratio of 0.35 .

8. Scaling of the airfoil cascade to a low (1.25) pressure ratio engine of the same total thrust gave 5 PNdB above the same $95 \mathrm{PNdB}$ goal while producing a reversed-to-forward thrust ratio of 0.65 . For a reversedto-forward thrust ratio of 0.4 , the calculated maximum $\mathrm{PNL}$ was around 95 PNdB.

9. A hard sideline shield used with the thin-vane reverser reduced maximum sideline PNL by as much as 6 PNdB. Addition of acoustic insulation to the shields and outer duct surfaces yielded an additional 2 PNdB reduction.

\section{Concluding Remarks}

The cascade configurations tested point out the difficulties of achieving low noise goals with thrust reversers for STOL applications. Based on the cold-flow model test results and the preliminary analysis reported herein, it may be possible to obtain thrust reversers (airfoilshaped cascade configuration plus sideline shielding) that approach the 95 PNdB sideline goal only with high bypass (low pressure ratio) exhausts. In general, reductions in the required reverse thrust will allow large reductions in reverser sideline noise by allowing operation at partial throttle settings. In addition, further investigation is useful in identifying cascade reverser geometry variables that will produce minimum perceived noise.

\section{Appendix - List of Symbols}

A

A ex

$A_{\text {ex }}^{\prime}$

An

$A_{\min }$

Area ratio $\equiv \mathrm{A}_{\text {ex }} / \mathrm{A}_{\text {in }}$

c cascade vane chord, in.

$c_{f} \quad$ reverse thrust coefficient, $c_{f} \equiv F_{r} / \mathscr{m}_{j} \cos \alpha$

co equivalent flow area of cascade, $A_{e} \equiv \dot{m} / \rho U_{j}$, in. ${ }^{2}$

total exit flow area of cascade assembly in direction of vane exit angle, defined by eq. (1), in. ${ }^{2}$

exit flow area of each cascade vane passage, in. ${ }^{2}$

total flow area in duct ahead of cascade assembly, in. ${ }^{2}$ minimum flow area, in. 2

speed of sound at atmospheric conditions, $\mathrm{ft} / \mathrm{sec}$ 


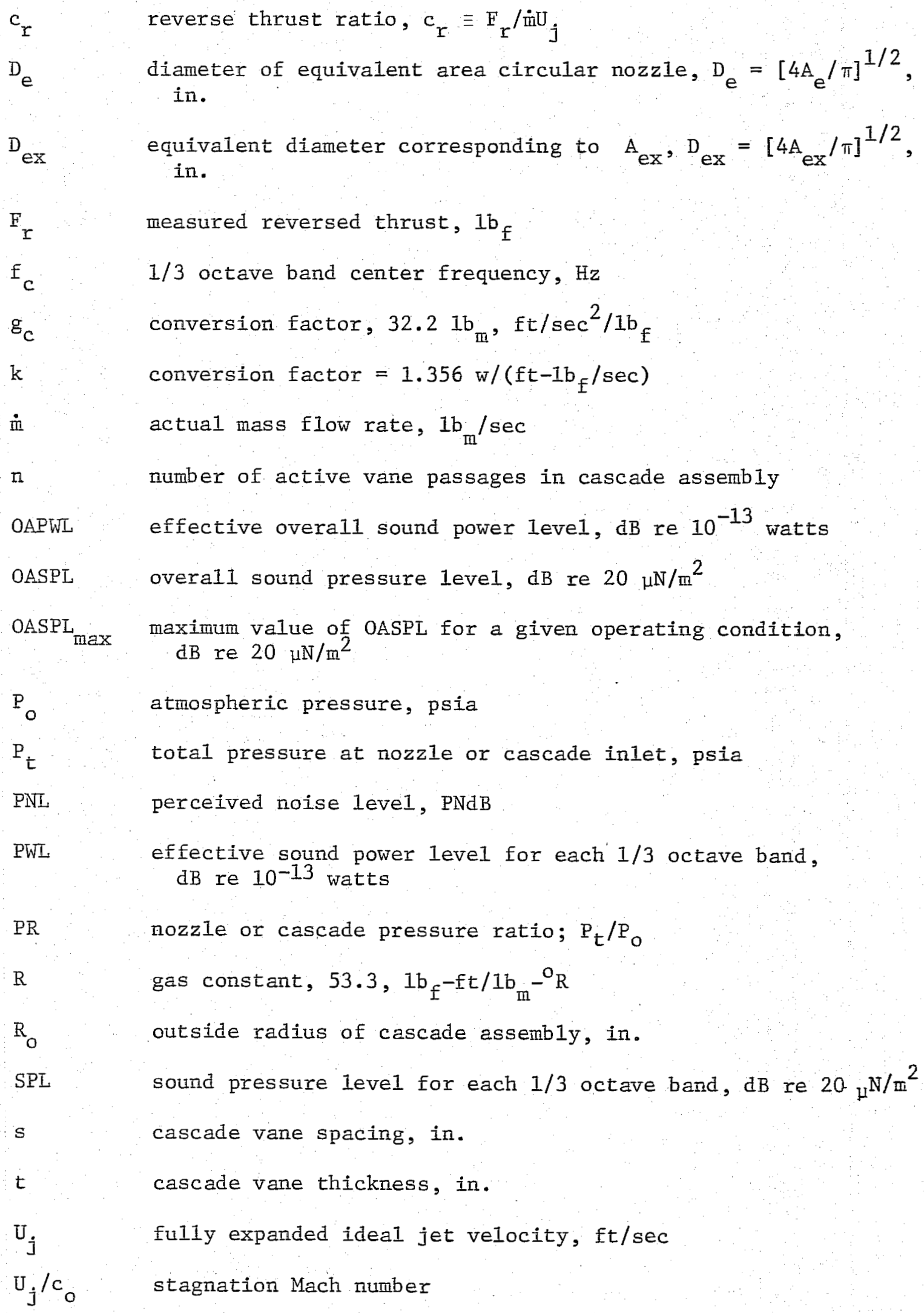


$\mathrm{W} \quad$ acoustic power, $\mathrm{W}=10^{\mathrm{OAPWL} / 10} / 10^{13}$, watts

$\alpha \quad$ cascade blade exit angle, deg

Q microphone polar angle measured from inlet axis, deg

$p$ air density at fully expanded jet conditions, $1 \mathrm{~b}_{\mathrm{m}} / \mathrm{ft}^{3}$

$\rho_{0}$ air density at ambient conditions, $1 \mathrm{~b}_{\mathrm{m}} / \mathrm{ft}^{3}$

\section{References}

1. Povolny, J. H., Steffan, F. W., and McArdle, J. G., "Summary of ScaleMode1 Thrust-Reverser Investigation," Rept. 1314, 1957, NACA.

2. Gutierrez, O. A. and Stone, J. R., "Preliminary Experiments on the Noise Generated by Target-Type Thrust Reverser Mode1s," TM X-2553, 1972, NASA.

3. Stone, J. R. and Gutierrez, O. A., "Noise Generated by STOL Core-Jet Thrust Reversers," AIAA Paper 72-791, Los Angeles, Calif., 1972; also TM X-68082, 1972, NASA.

4. Stone, J. R. and Gutierrez, 0. A., "Sma11-Scale Noise Tests of a Slot Nozzle with V-Gutter Target Thrust Reverser," TM X-2758, 1973, NASA.

5. Stone, J. R., and Gutierrez, O. A., "Noise Tests of a High-AspectRatio Slot Nozzle with Various V-Gutter Target Thrust Reversers," TM X-71470, 1973, NASA.

6. Fink M. R., "Thrust Reverser Noise Estimation," Journal of Aircraft, vol. 10, No. 8, Aug. 1973, pp. 507-508.

7. Dietrich, D. A. and Luidens, R. W., "Experimental Performance of Cascade Thrust Reversers at Forward Velocity, TM X-2665, 1973, NASA.

8. Huff, R. G. and Groesbeck, D. E., "Splitting Supersonic Nozzle Flow into Separate Jets by Overexpansion into a Multilobed Divergent Nozzle," TN D-6667, 1972, NASA.

9. Vsn Glahn, U.; Goodykcontz, J.; and Wagner, J.: Nozzle Geometry and Forward Velocity Effects on Noise for CTOL Engine-Over-the-Wing Concept. NASA TM X-71453, 1973.

10. Anon., "Noise Standards: Aircraft Type Certification," Federal Aviation Regulations, Vol. ITI, Pt. 36, 1969.

11. Anon., "Definitions and Procedures for Computing the Perceived Noise Level of Aircraft Noise," Aerospace Recommonded Practice 865A, Aug. 15, 1969, SAE. 

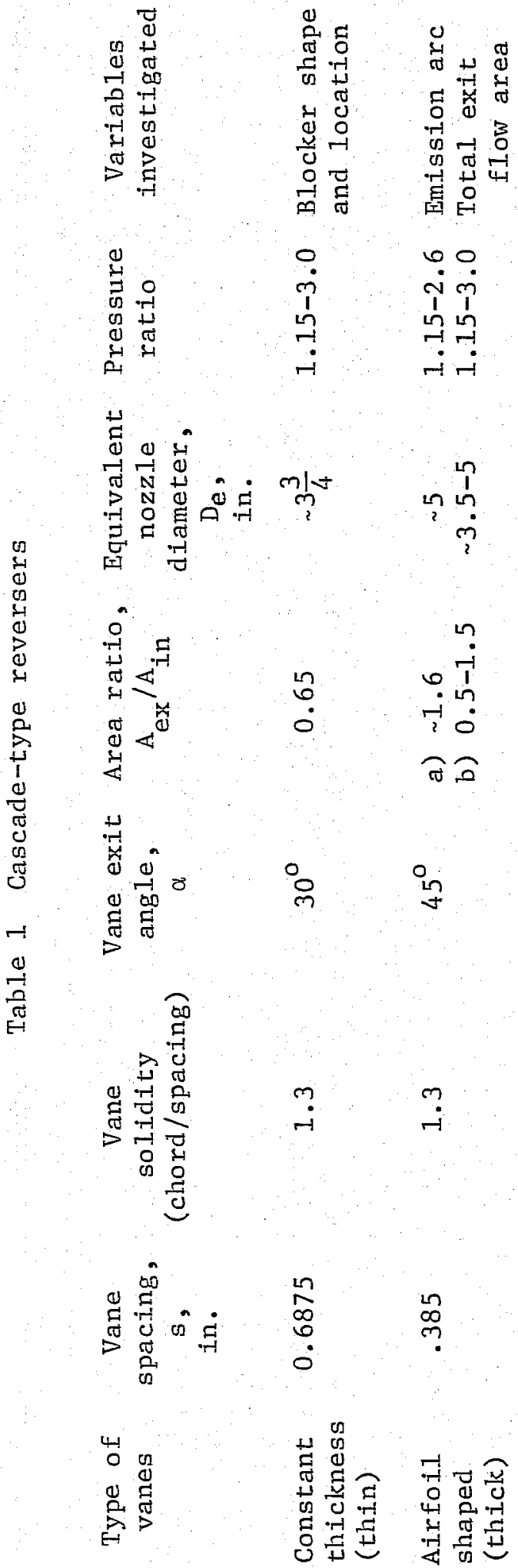

Table 3 Ratio of effective area to exit area, $A_{e} / A_{e x}$, for the varfous cascade configurations

Table 2 Vartations of airfoli-vaned cascade configurations

\begin{tabular}{|c|c|c|c|c|c|c|c|}
\hline \multirow[t]{2}{*}{ Sertes } & \multirow[t]{2}{*}{ Identification } & \multirow{2}{*}{$\begin{array}{l}\text { Efflux } \\
\text { arc }\end{array}$} & \multirow{2}{*}{$\begin{array}{l}\text { Number of } \\
\text { segments }\end{array}$} & \multirow{2}{*}{$\begin{array}{c}\text { Number of } \\
\text { active } \\
\text { vanes, } \\
n\end{array}$} & \multirow{2}{*}{$\begin{array}{l}\text { Exit } \\
\text { area, } \\
\text { Aex, } \\
\mathrm{An}^{2}\end{array}$} & \multicolumn{2}{|c|}{ Area ratio, s } \\
\hline & & & & & & $A_{e x} / A_{1 n}$ & $A_{\min } / A_{e x}$ \\
\hline $\begin{array}{l}\text { Vartable } \\
\text { emisstion } \\
\text { arc }\end{array}$ & -5 & $340^{\circ}$ & 8 & 5 & 26.75 & 1.25 & 0.795 \\
\hline & -9 & $21.5^{\circ}$ & 6 & 9 & 36.10 & 1.68 & .595 \\
\hline$\downarrow$ & -9 & $21.5^{\circ}$ & 6 & 9 & 36.10 & 1.68 & .595 \\
\hline $\begin{array}{l}\text { lartable } \\
\text { flow } \\
\text { area }\end{array}$ & -12 & $170^{\circ}$ & 4 & 12 & 32.09 & 1.49 & 0.670 \\
\hline & -8 & 1 & 1 & 8 & 21.39 & .99 & .755 \\
\hline & -6 & & & 6 & 16.04 & .75 & 1 \\
\hline & -5 & & & 5 & 13.37 & .62 & \\
\hline & -4 & $\checkmark$ & $\downarrow$ & 4 & 10.70 & .50 & $\downarrow$ \\
\hline
\end{tabular}

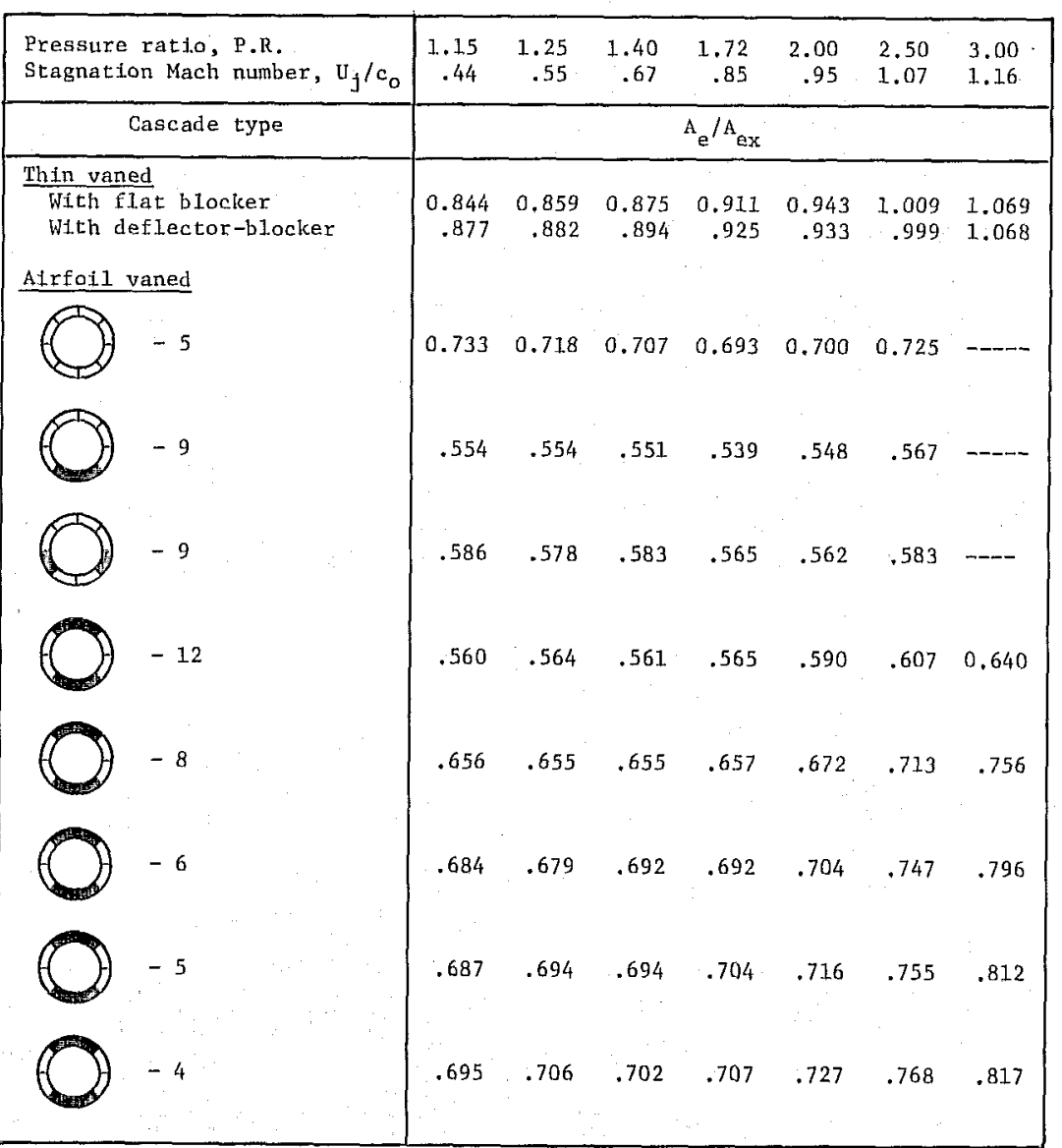

Ro 


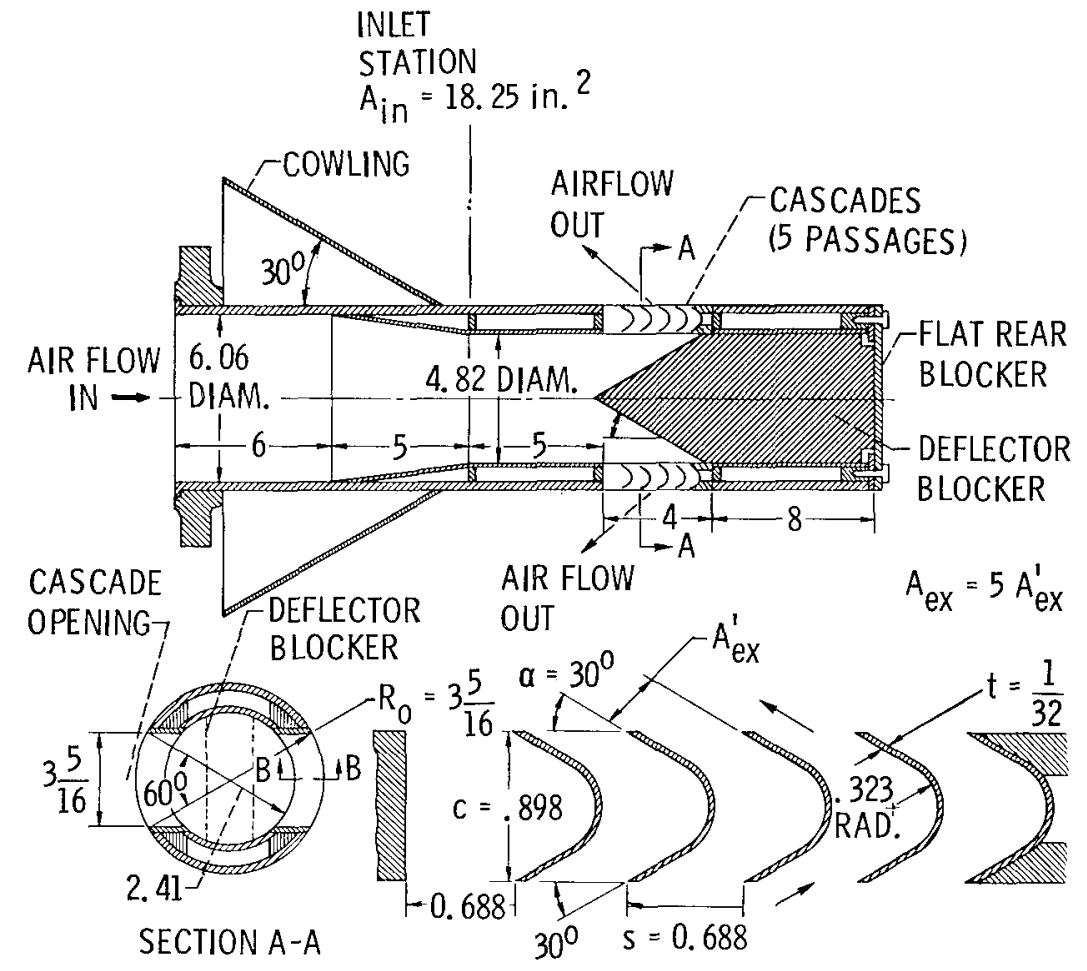

$[1$
1
$\infty$
$a$
1

SECTION B-B

Figure 1. - Sketch of cascade reverser with thin vanes. (All dimensions in in. ).

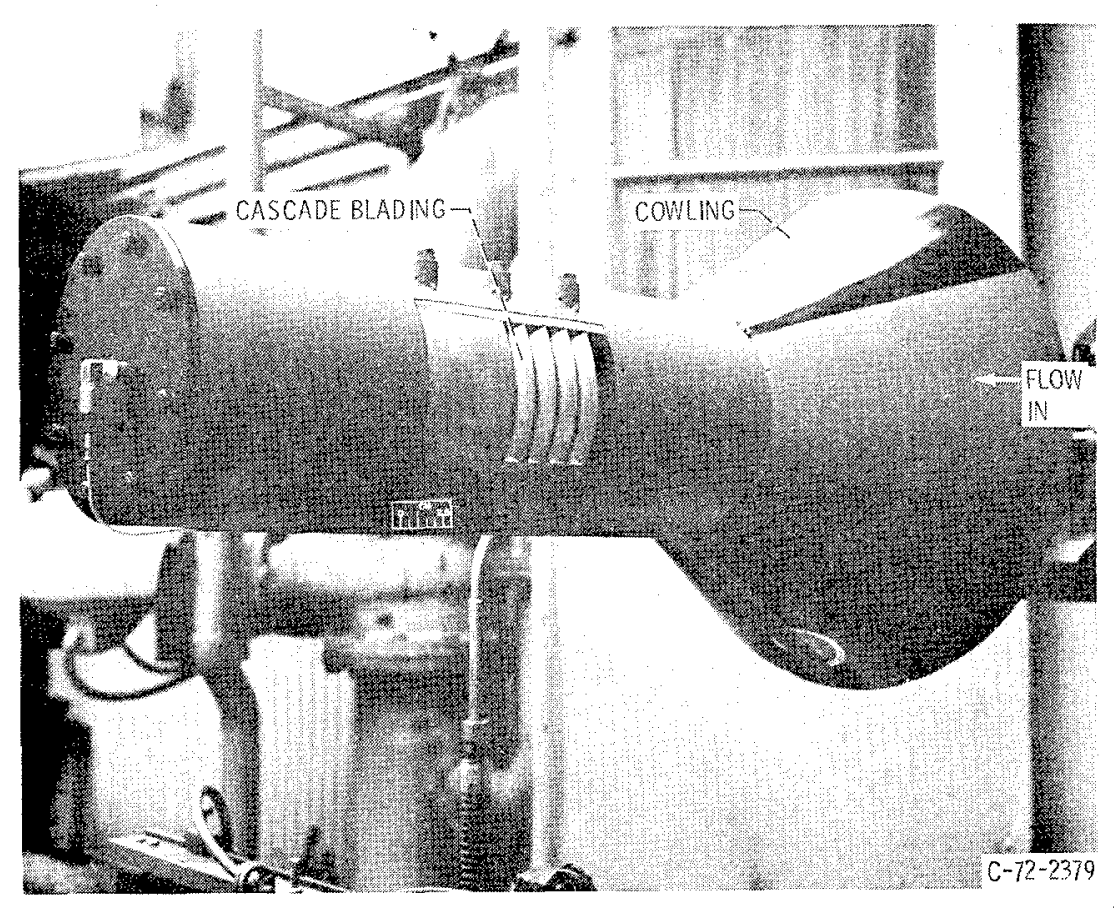

Figure 2. - Cascade reverser with thin constant-thickness vanes. 


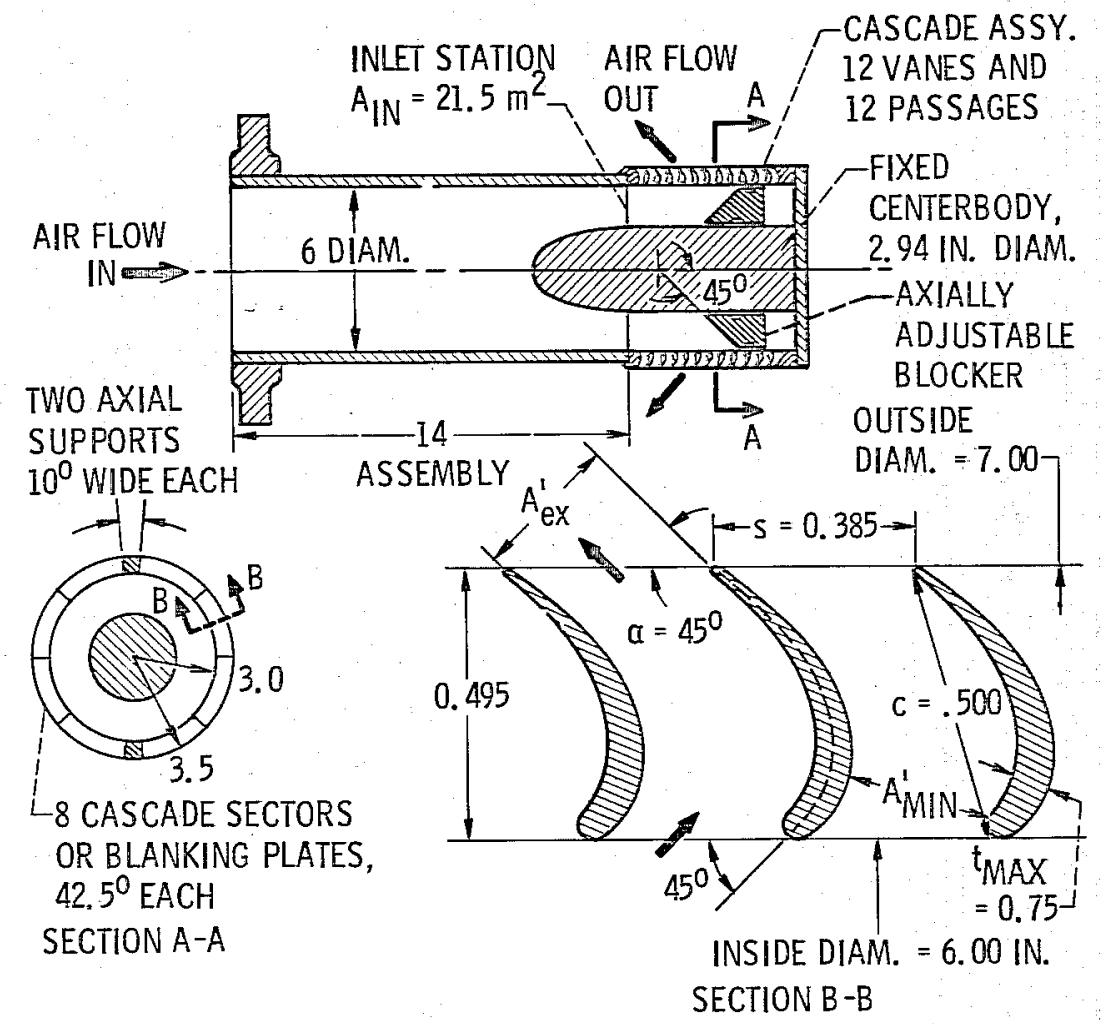

Figure 3. - Sketch of cascade reverser with airfoil shaped vanes.

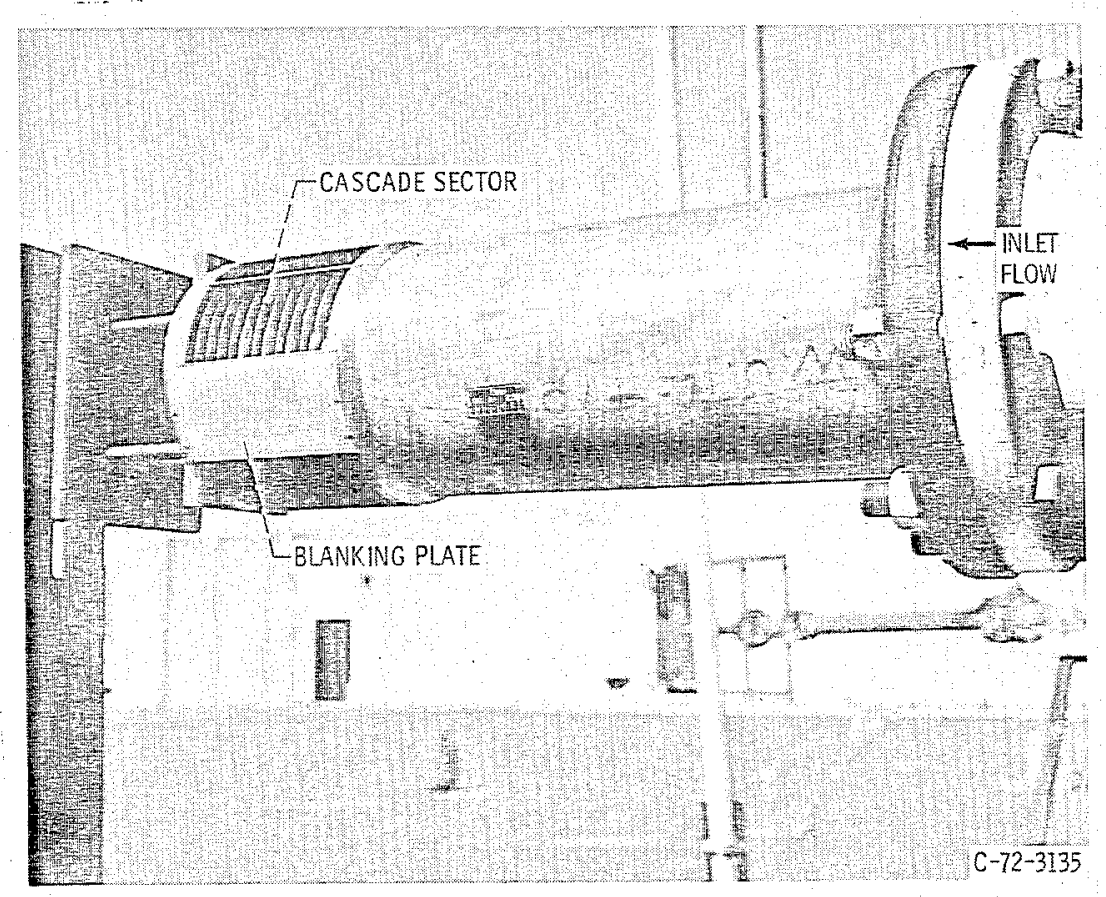

Figure 4. - Cascade reverser with air foil shaped vanes. 


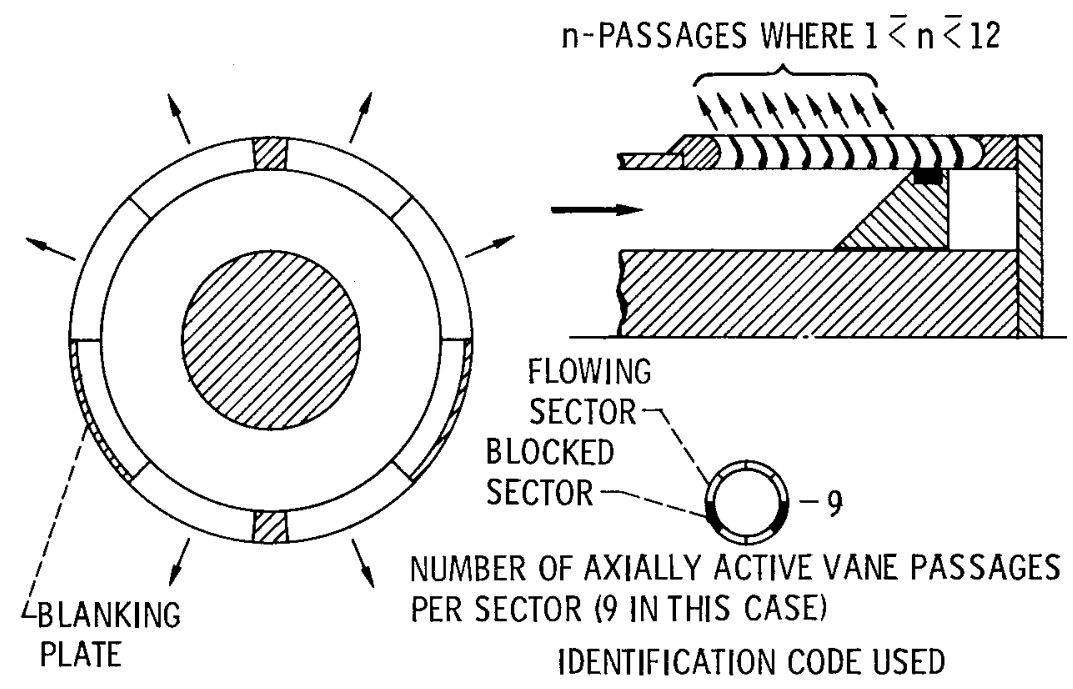

Figure 5. - Identification of configurations for cascade with air foil shaped vanes.

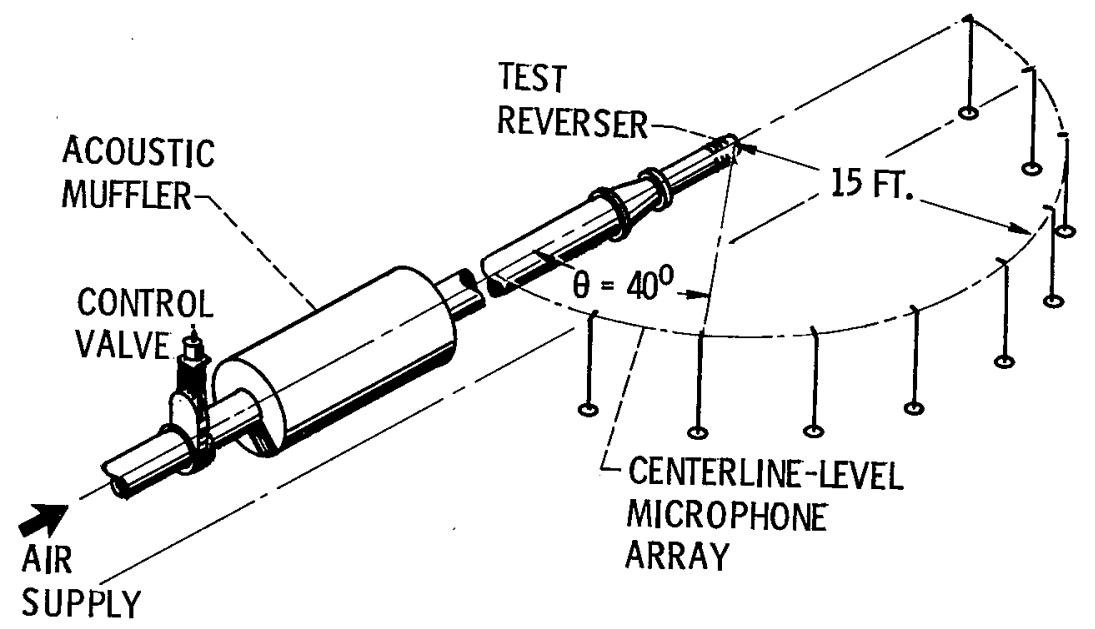

Figure 6. - Schematic diagram of acoustic rug. 


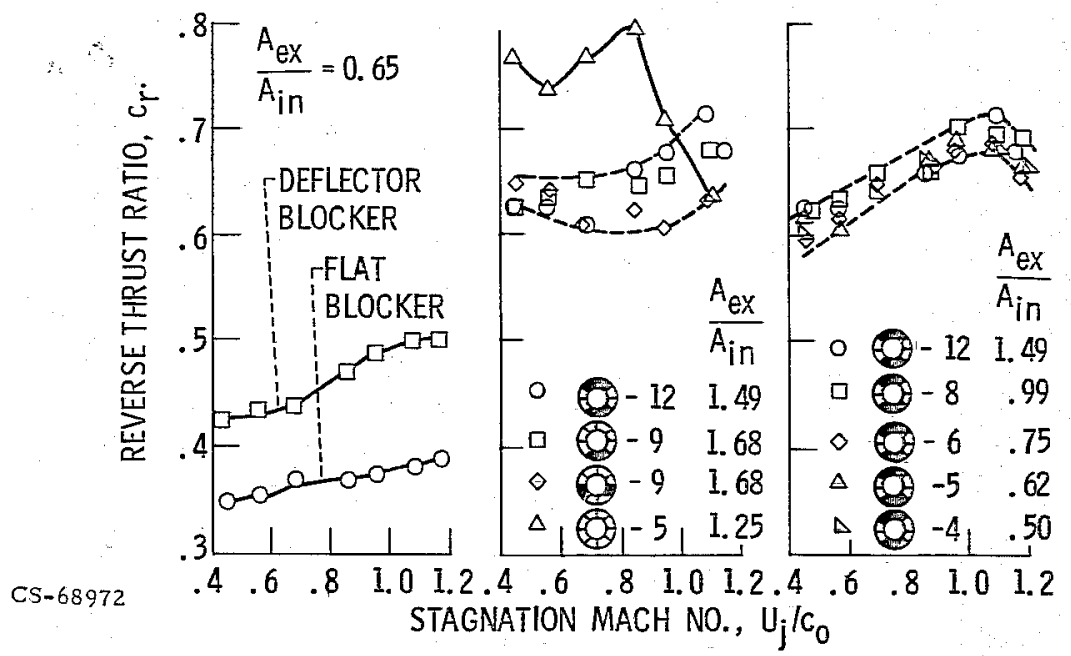

4
0
0
5
1
fi
(a) THIN-VANED
( (b) AIRFOIL-SHAPED
(c) AIRFOIL-SHAPED CASCADE. CASCADE VARI- CASCADE VARI- ABLE EMISSION ABLE AREA. ARC.

Figure 7. - Cascade reversed thrust coefficient as a function of stagnation Mach number $\mathrm{U}_{\mathrm{j}} / \mathrm{c}_{0}$. 


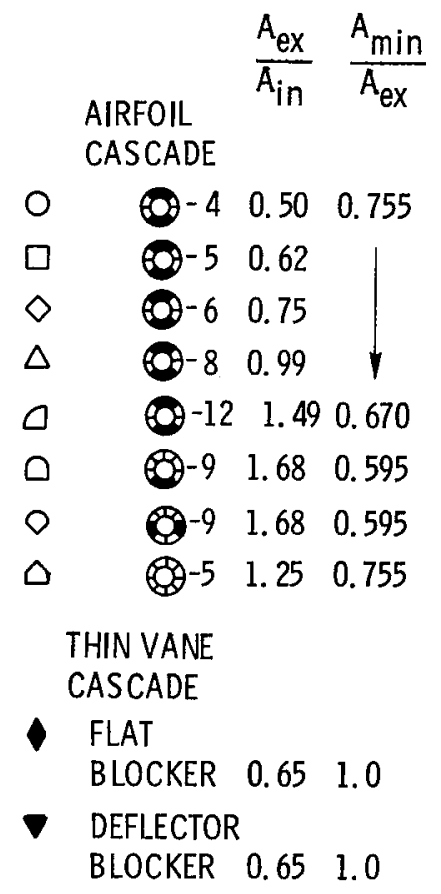

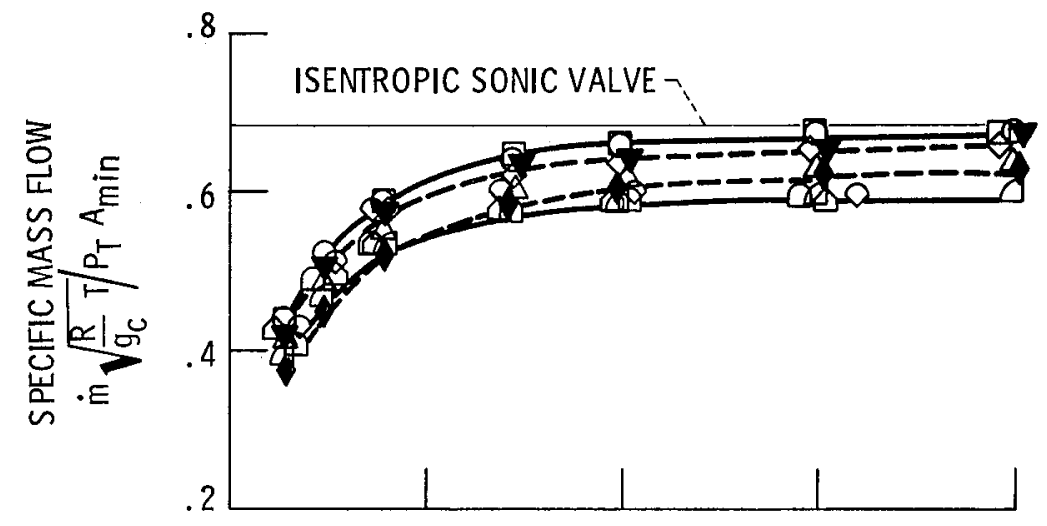

1
1
$\infty$
0
$\Delta$

(a) SPECIFIC MASS FLOW.

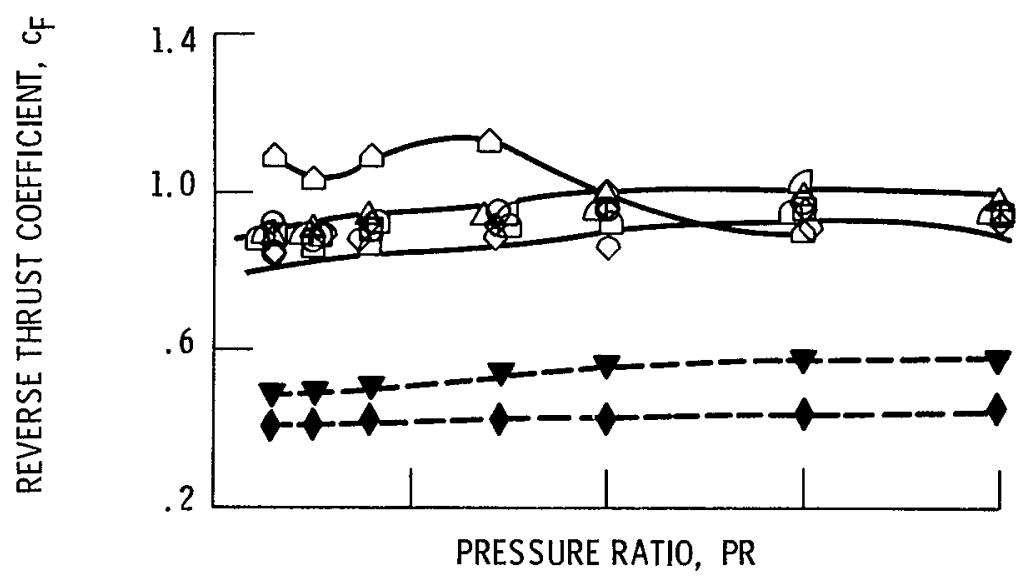

(b) REVERSE THRUST COEFFICIENT.

Figure 8. - Aerodynamic characteristics of cascade reversers. 


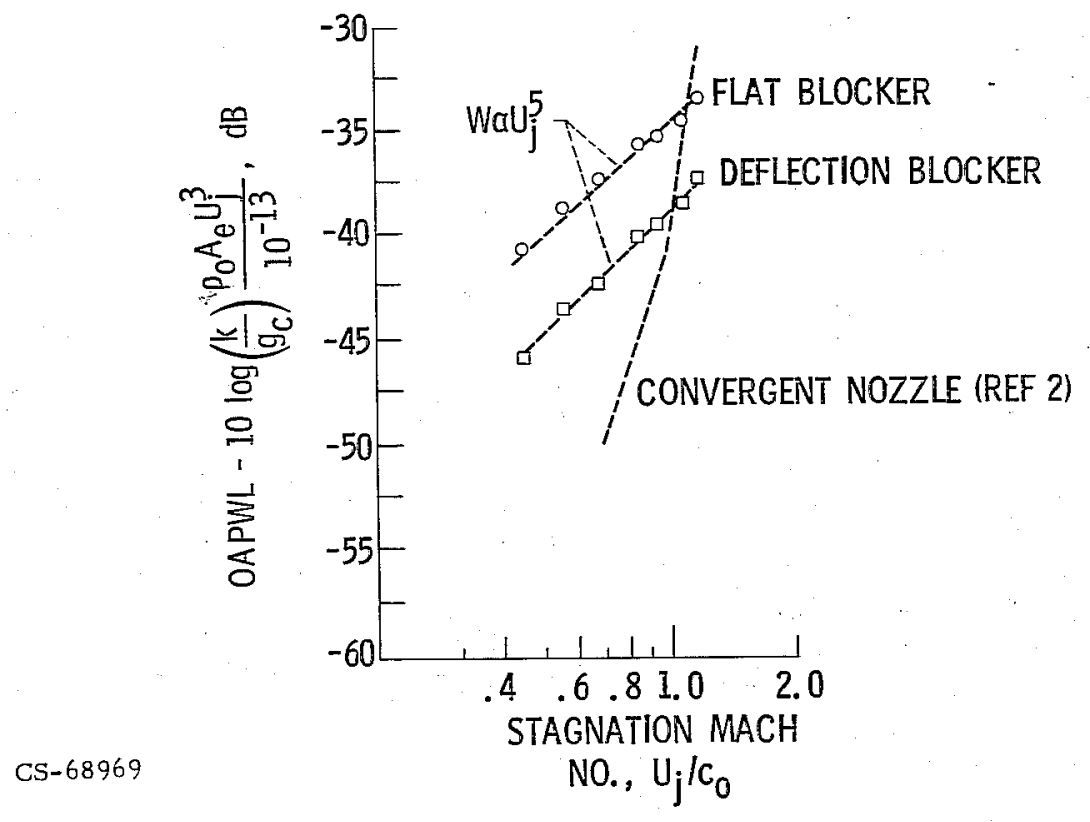

Figure 9. - Normalized overall sound power level for thin-vaned cascade reversers.

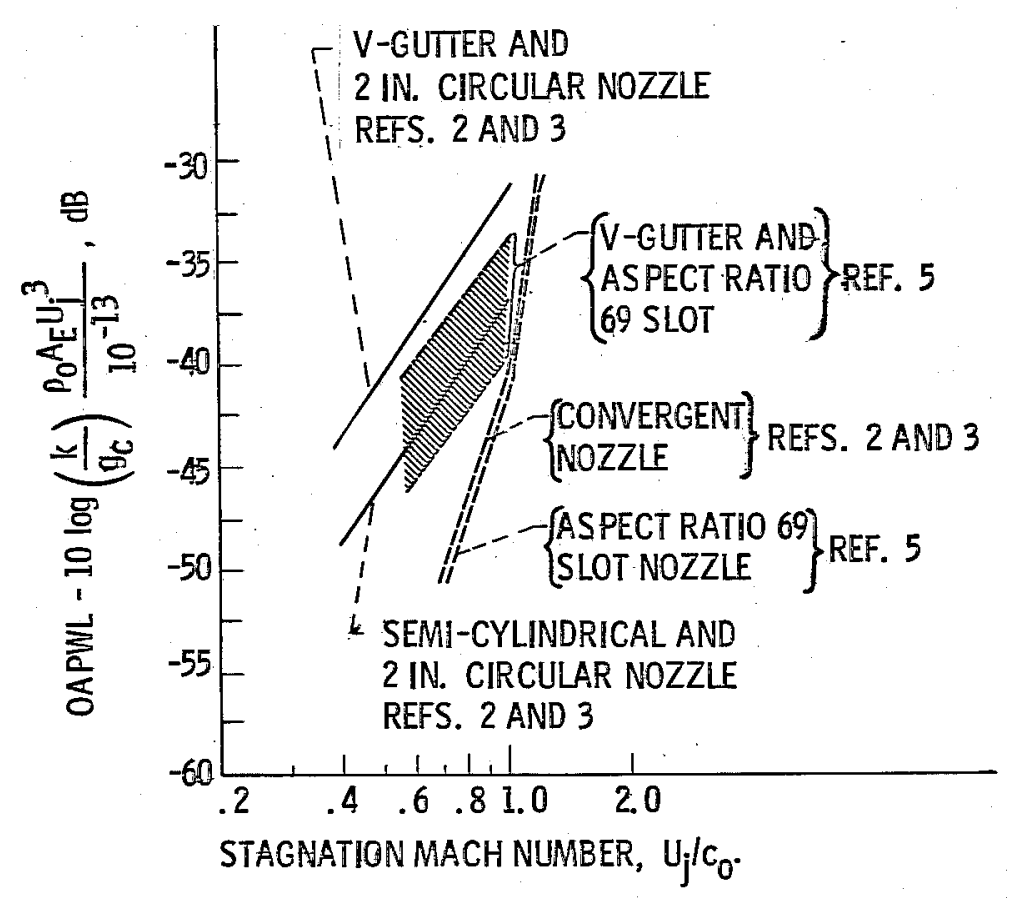

Figure 10. - Normalized overall sound power levels for various target reversers. 


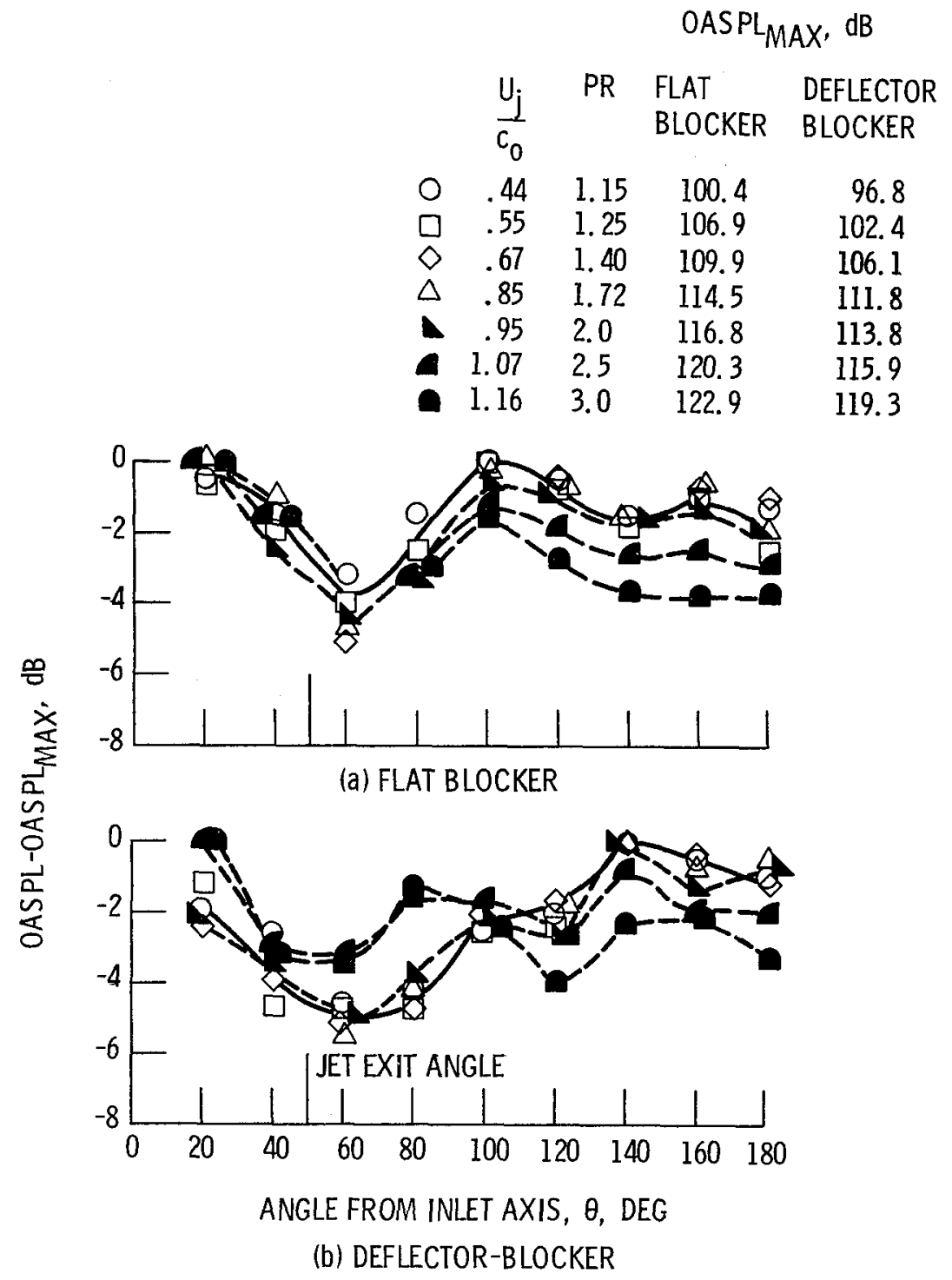

Figure 11. - Noise directivity of thin-vaned cascade reverser. $A_{e x} / A_{\text {in }}=0.65$. 


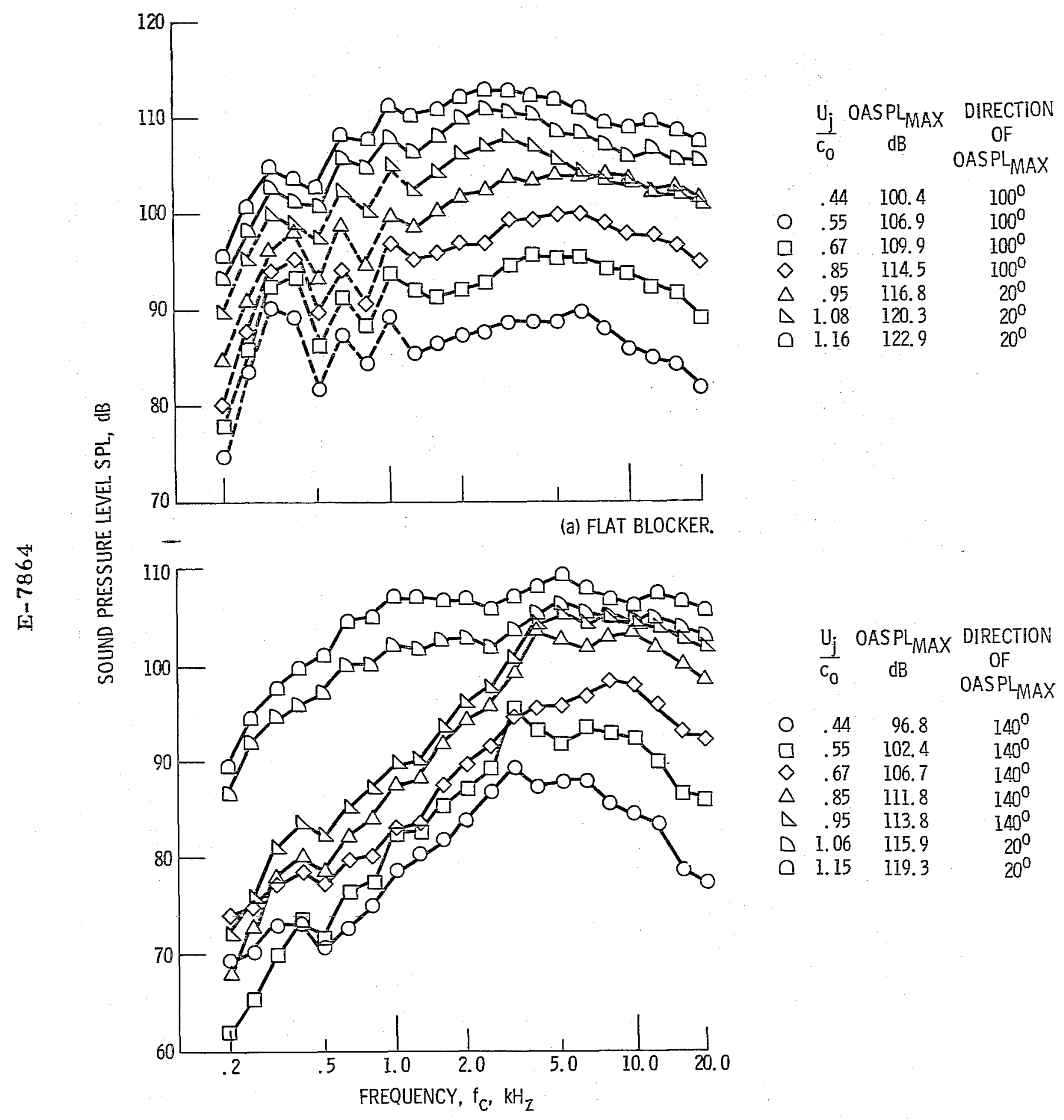

(b) DEFLECTOR-BLOCKER.

Figure 12. - Sound pressure level spectra at maximum OASPL direction for thin vaned cascade reversers. 


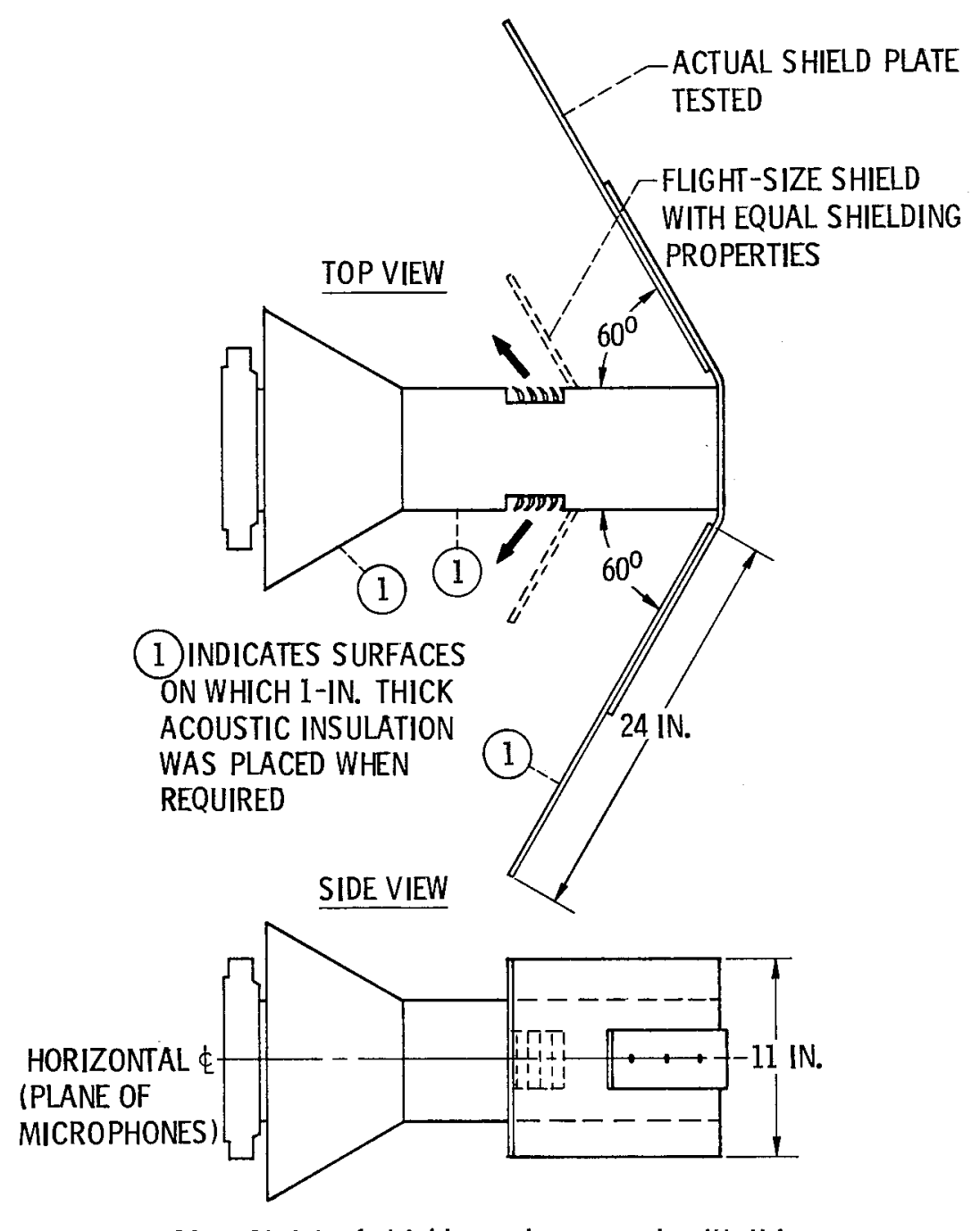

Figure 13. - Sketch of shields used on cascade with thin vanes.
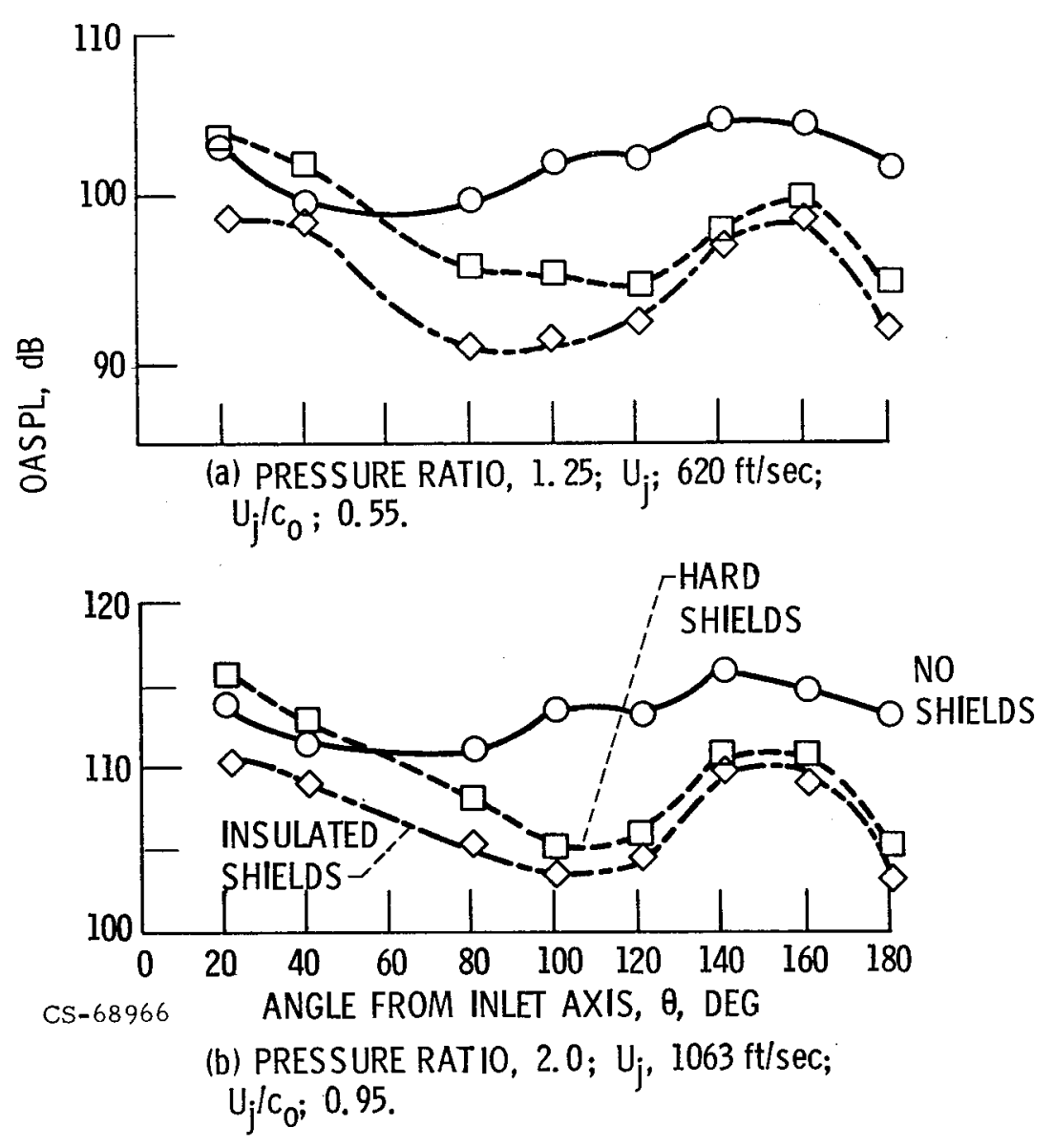

Figure 14. - Effect of sideline shielding on overall sound pressure level for thin-vaned cascade with deflector blocker. 


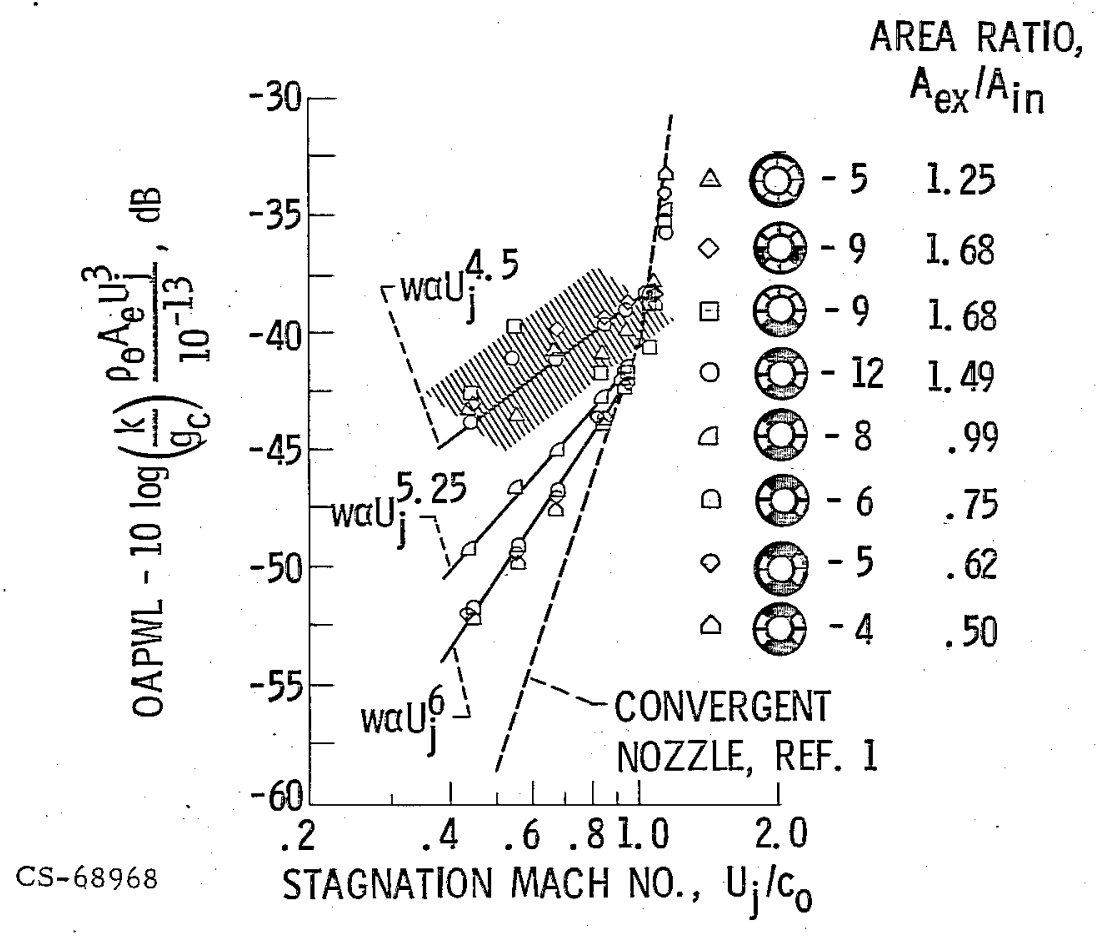

Figure 15. - Normalized overall sound power level for airfoil-shaped cascade reverser.

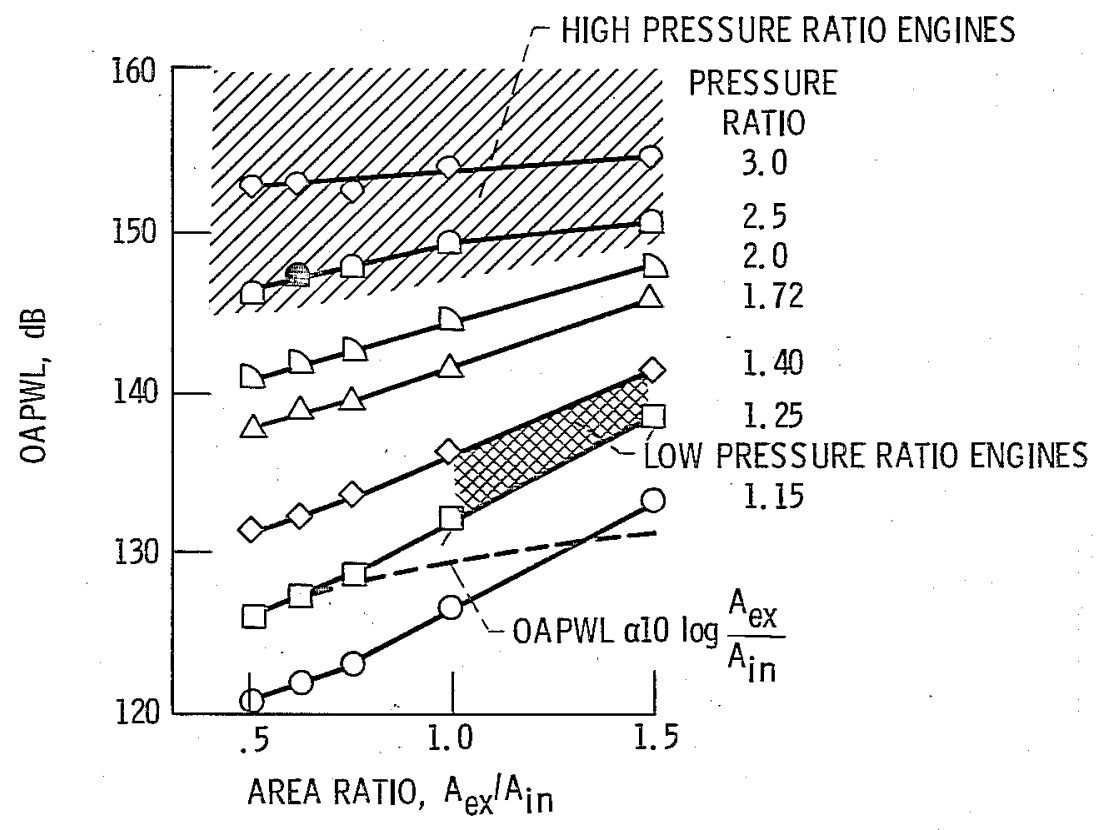

Figure 16. - Overall sound power level as a function of exit area ratio, $A_{e x} / A_{i n}$ for airfoil vaned cascade. Emission arc; $170^{\circ}$; $A_{\text {IN }} ; 21.5 \mathrm{in}^{2}$. 


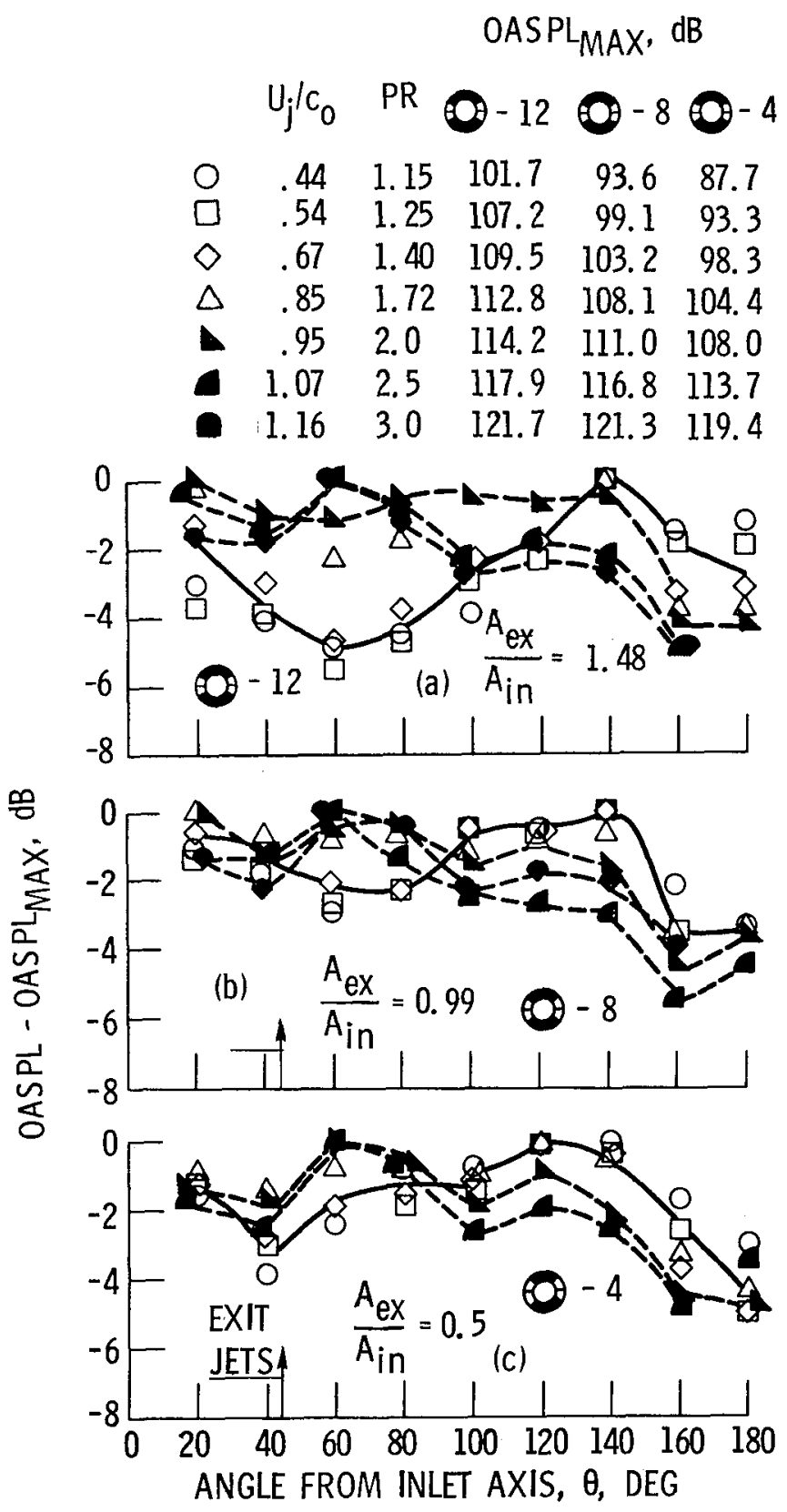

1
1
0
0
1

Figure 17. - Noise directivity of airfoil-shaped cascade reverser. Emission arc $=170^{\circ}$. 


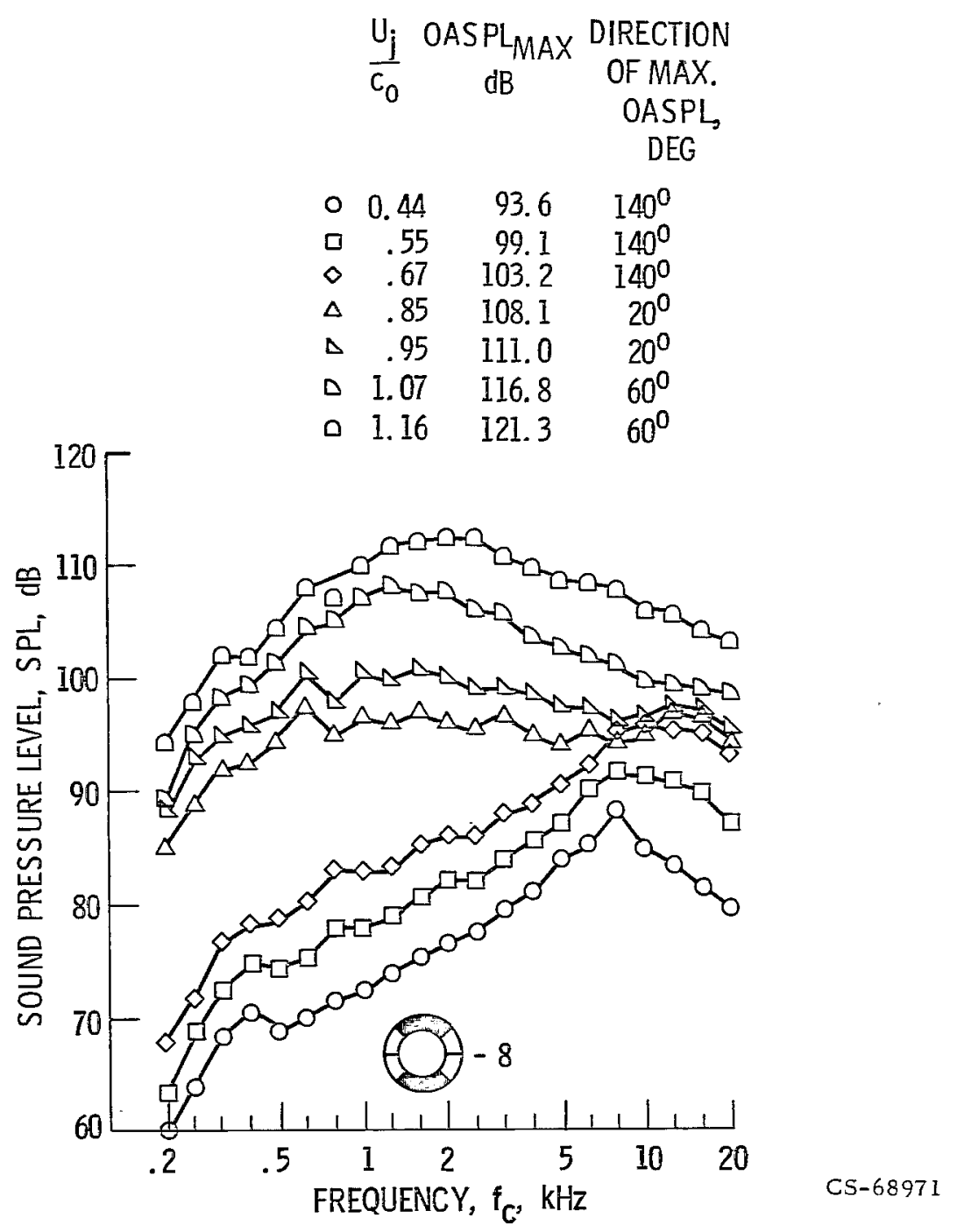

Figure 18. - Sound pressure level spectra at maximum OASPL direction for airfoil-shaped cascade reverser. $170^{\circ}$ emission arc, 8 vanes; $A_{e x} / A_{i n}=0.99$. 


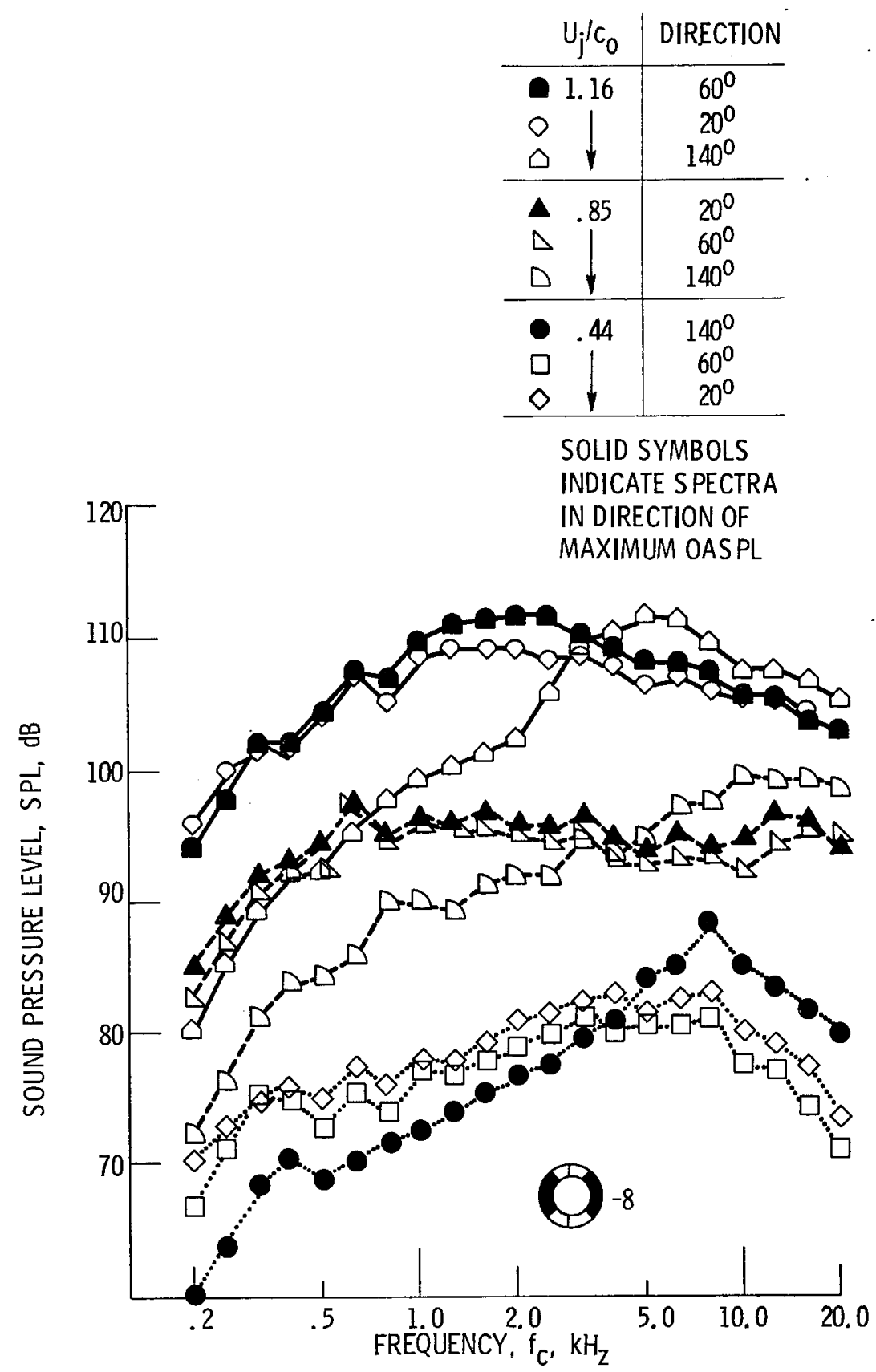

Figure 19. - Comparison of SPL spectra at angles of $20^{\circ}, 40^{\circ}$ and $140^{\circ}$ for airfoil-shaped cascade reverser. $170^{\circ}$ emission arc; 8 vanes; $A_{e x} / A_{i n}, 0.99$. 

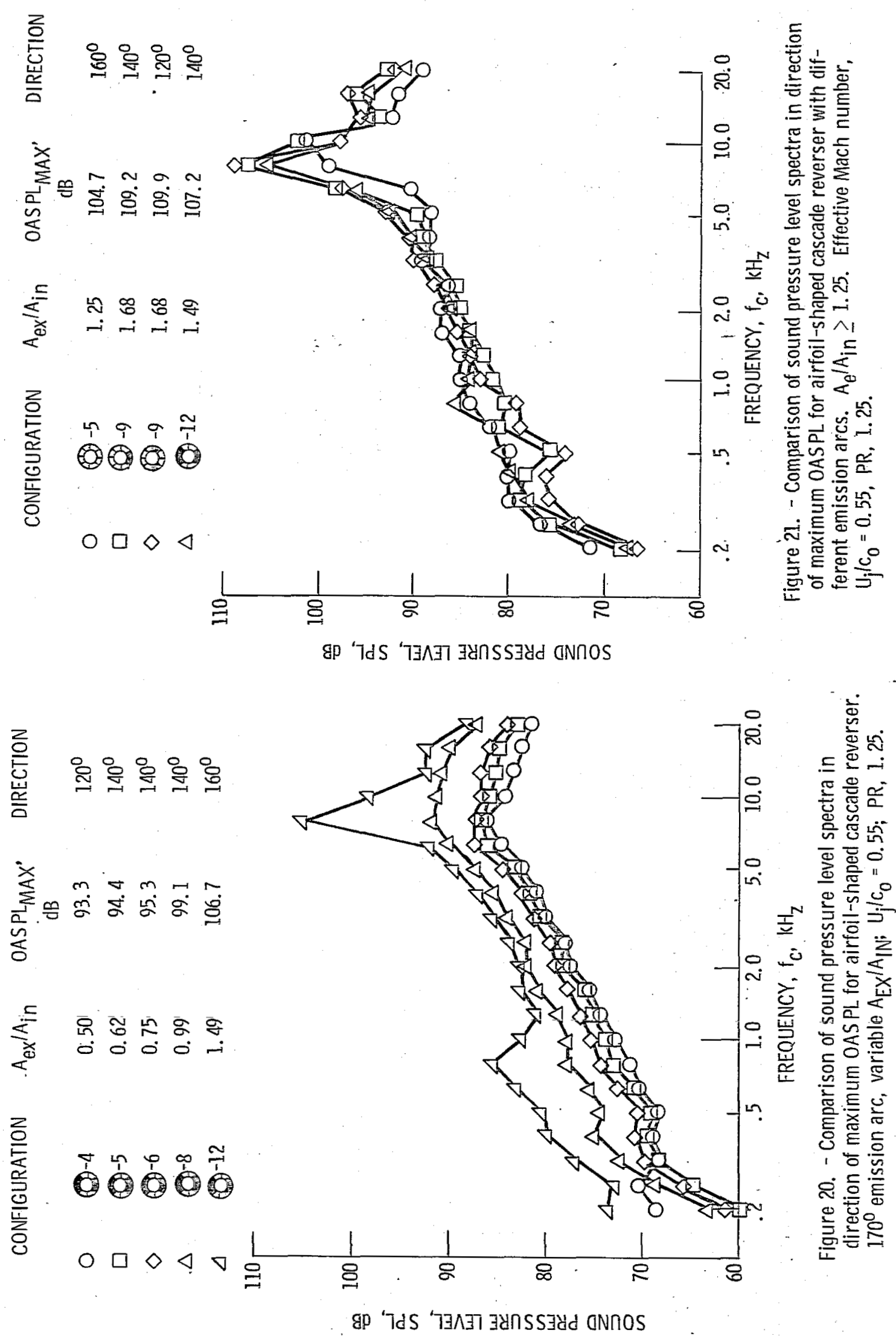

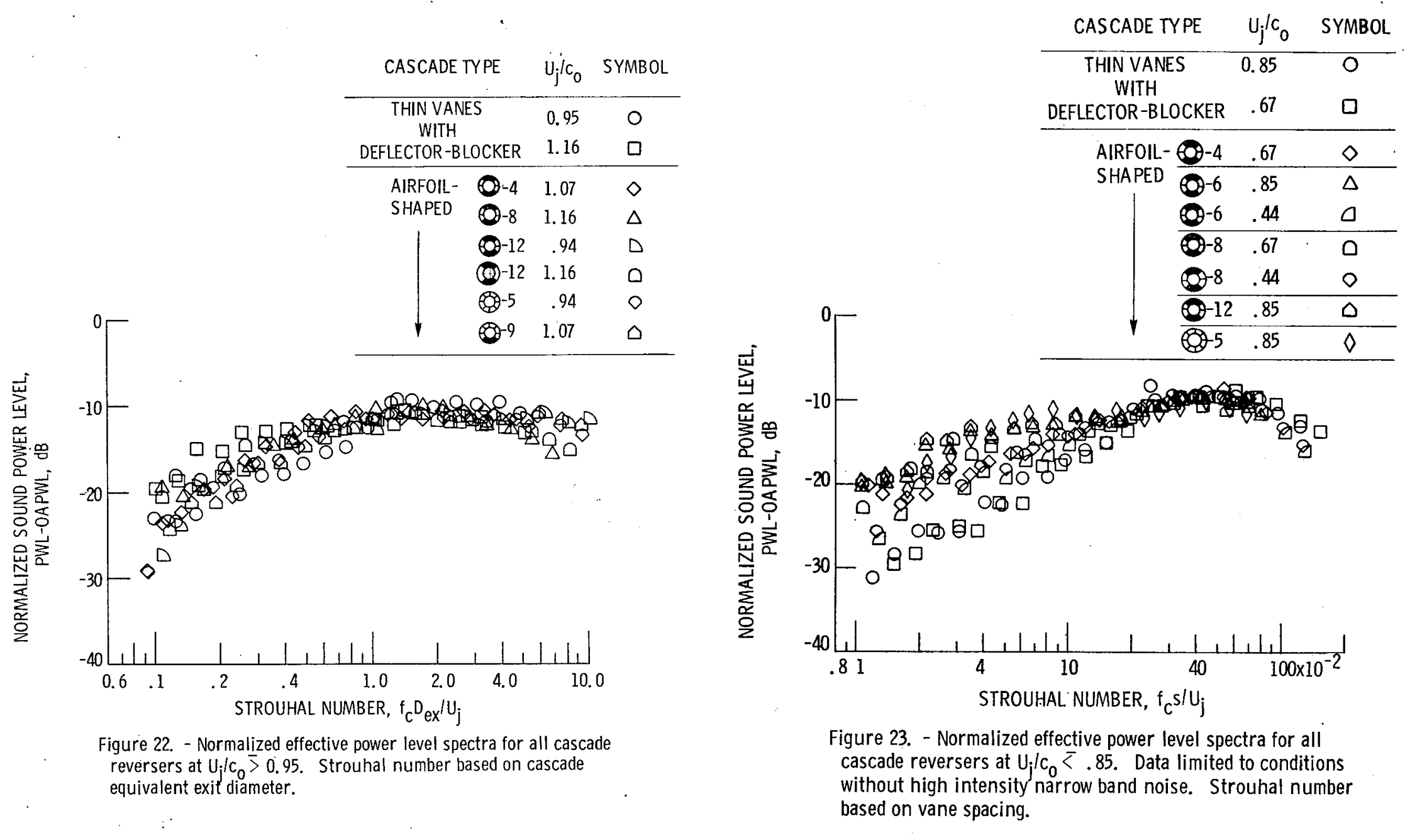


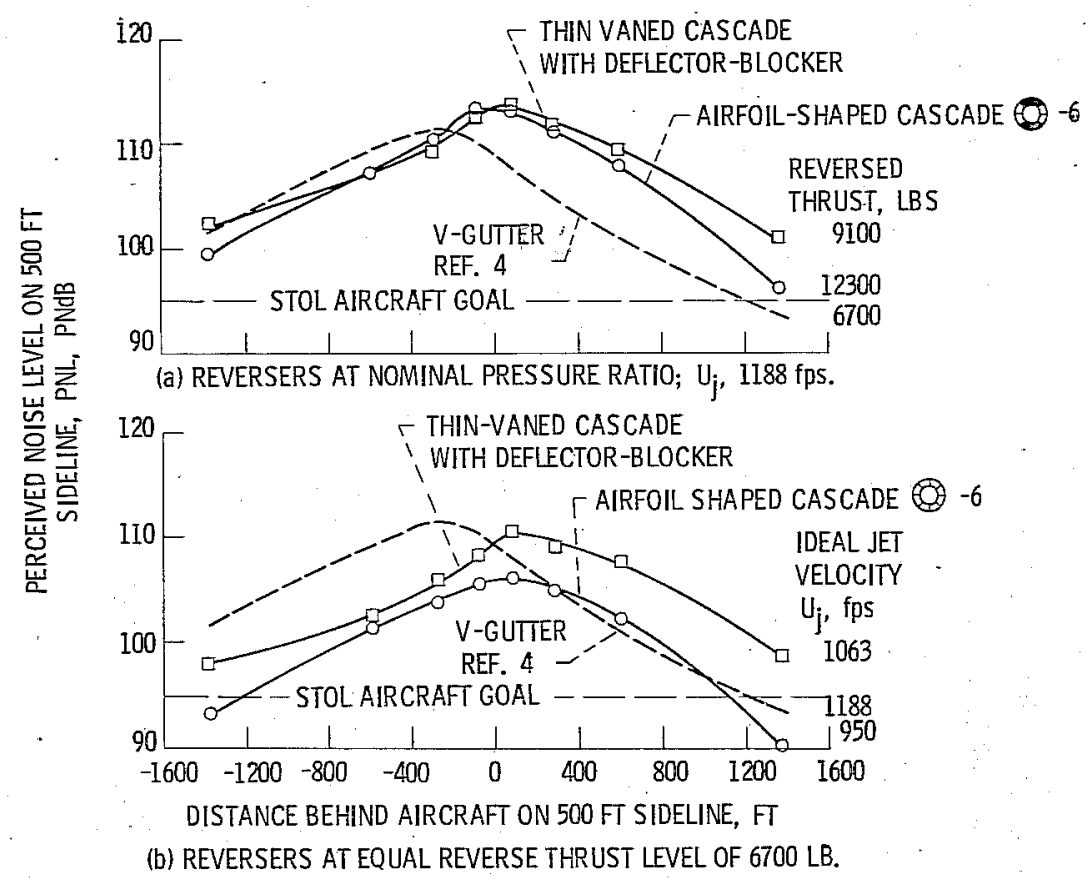

Figure 24. - Sideline noise for different reversers applied to a $19,000 \mathrm{lb}$. thrust engine. Nominal full throttle pressure ratio: 2.5; forward thrust nozzle equivalent diameter: 28 inches.

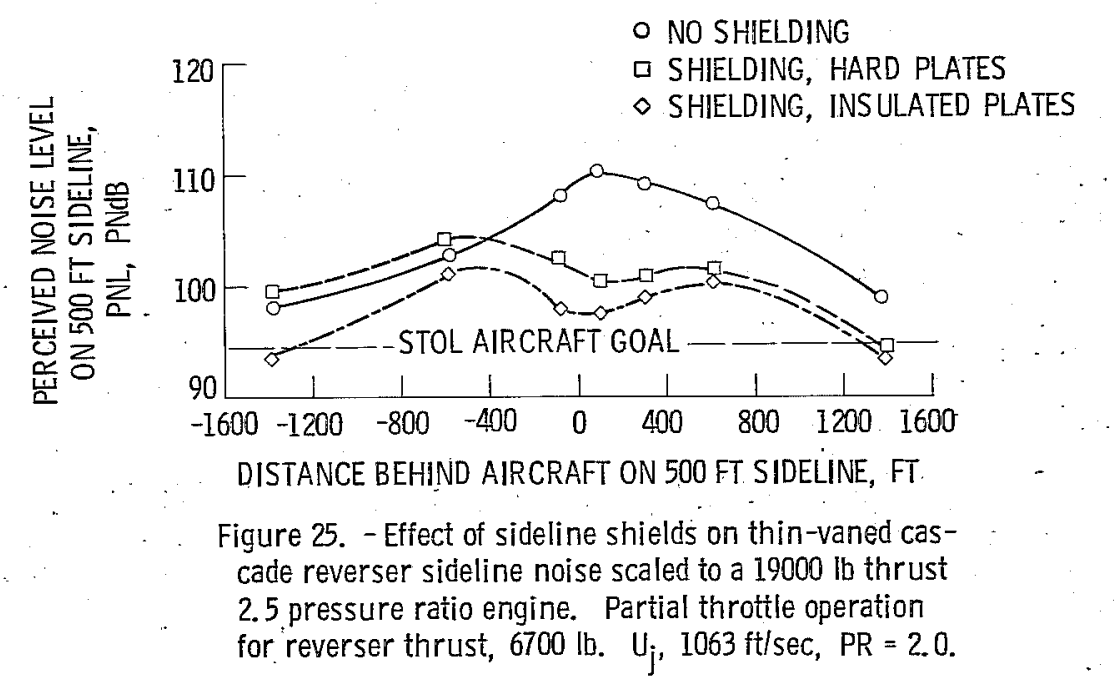




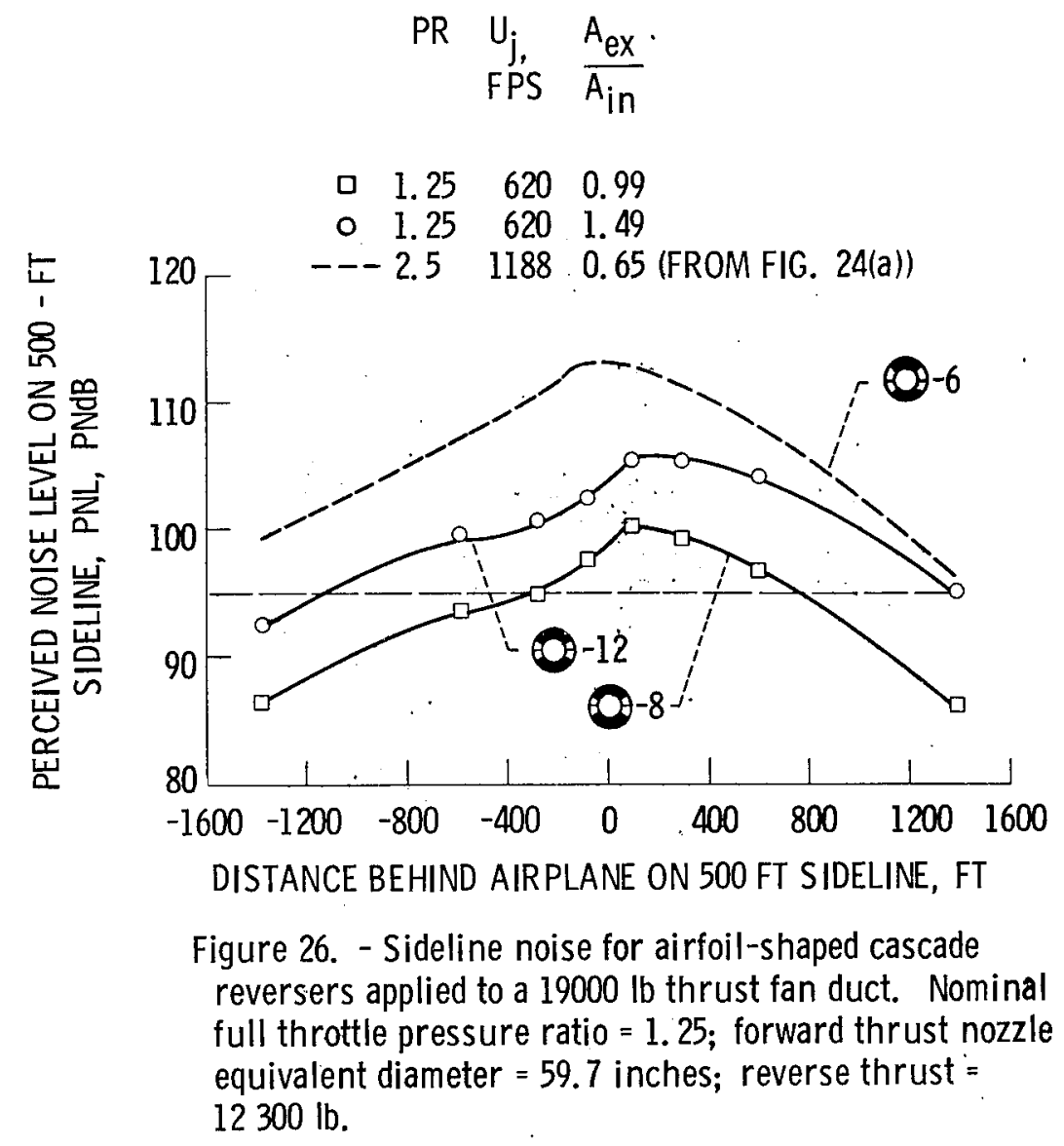

